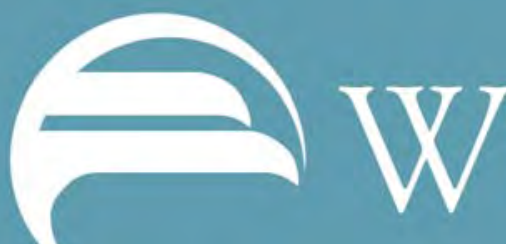 ORKING PAPERS
}

RESEARCH DEPARTMENT

\section{WORKING PAPER NO. 11-23 \\ THE DYNAMICS OF PUBLIC INVESTMENT UNDER PERSISTENT ELECTORAL ADVANTAGE}

Marina Azzimonti

Federal Reserve Bank of Philadelphia

June 2011

Research Department, Federal Reserve Bank of Philadelphia

Ten Independence Mall, Philadelphia, PA 19106-1574 • www.philadelphiafed.org/research-and-data/ 


\title{
THE DYNAMICS OF PUBLIC INVESTMENT UNDER PERSISTENT ELECTORAL ADVANTAGE.*
}

\author{
Marina Azzimonti ${ }^{\dagger}$
}

This version: June 2011

\begin{abstract}
This paper studies the effects of asymmetries in re-election probabilities across parties on public policy and its subsequent propagation to the economy. The struggle between opposing groups-that disagree on the composition of public consumption-results in governments being endogenously short-sighted: Systematic under investment in infrastructure and overspending on public goods arise, as resources are more valuable when in power. Because the party enjoying an electoral advantage is relatively less short-sighted, it devotes a larger proportion of government revenues to productive public investment. Political turnover, together with asymmetric policy choices, induces economic fluctuations in an otherwise deterministic environment. I characterize the long-run distribution of capital and show that output increases on average with political advantage, despite the fact that the size of the government expands as a percentage of GDP. Volatility, on the other hand, is non-monotonic in political power and is an additional source of inefficiency.
\end{abstract}

JEL Classification: E61, E62, H11, H29, H41, O23

Keywords: Public Investment, Commitment, Probabilistic Voting, Markov Equilibrium, Political Cycles, Time Consistency, Electoral Advantage, Ideological Bias.

*An earlier version of this paper circulated under the title 'On the dynamic inefficiency of governments.' I would like to thank Marco Battaglini, Steve Coate, Per Krusell, Antonio Merlo, and Pierre Yared for useful comments. Part of this work was developed while visiting the IIES at Stockholm University and the University of Pennsylvania. All errors are mine.

${ }^{\dagger}$ FRB of Philadelphia - Research Department. Email: marina.azzimonti@phil.frb.org. The views expressed in this paper are those of the author and do not necessarily reflect those of the Federal Reserve Bank of Philadelphia or the Federal Reserve System. This paper is available free of charge at www.philadelphiafed.org/research-and-data/publications/working-papers/ 


\section{Introduction}

A central issue in dynamic political economy is to understand how political frictions affect fiscal policy and economic performance over time. The recent literature has focused almost exclusively on characterizing symmetric equilibria in which parties behave identically. A main result is that re-election uncertainty introduces a wedge in intertemporal decisions when governments lack commitment. This wedge distorts economic allocations; thereby reducing long-run output and consumption. This paper contributes to the literature by considering the implications of asymmetries in election probabilities between competing parties. Additional distortions emerge when incumbents face different re-election prospects, since the politically disadvantaged party leans toward more short-sighted policies. Alternating power induces economic fluctuations via changes in taxation and spending (in an environment that is otherwise deterministic), furthering the inefficiencies. I find that the resulting volatilities are non-monotonic in the size of the political bias.

Persistent partisan advantage in democratic elections has been extensively documented by political scientists, in particular regarding the voting behavior across US states. Using a multi-component index that combines historical results in gubernatorial, House, and Senate elections, individual states are characterized being under Democratic or Republican control. Brown and Bruce (2008) use a combination of the two most common indices of political competition, the Ranney index and the Holbrook Van Dunk index, to compute trends in political advantage. Their study shows that between 1968 and 2003, Massachusetts, Maryland, and New York exhibit a sizeable and uninterrupted Democratic advantage (both at the state and national levels). New Hampshire, Wyoming, and Indiana, on the other hand, have been exclusively under Republican control. Using the index in Diermeier, Keane, and Merlo (2005) I document that the Democratic party has shown an average advantage during the period 1929 - 2006 at the national level. Evidence of systematic electoral biases in other countries is further illustrated by the recent experiences of Japan and Mexico. Despite the body of research showing that party advantage is fairly common and empirically relevant, the possibility of asymmetries in election prospects have been ignored in dynamic political economy models. Understanding its implications is a main objective of this work.

Building on the work of Alesina and Tabellini (1990) and Besley and Coate (1998), I present a theoretical model in which partisan electoral advantage is explicitly considered. There are two groups of citizens in the economy that disagree on the provision of local public goods but have common interests regarding the accumulation of public capital, which enhances output. Groups are represented by parties that alternate in power via a democratic process. A key feature is that a representative of only one of the groups is in power at each point in time and suffers from limited commitment. I characterize time-consistent policies as Markov-perfect equilibria. Because election outcomes are uncertain, parties are endogenously short-sighted - at least more so than the groups they represent. Thus, despite the fact that financing instruments are non-distortionary (i.e., taxes are lump-sum), an intertemporal wedge arises. Policymakers tend to overspend in public consumption and underinvest on productive public capital, which reduces output and private consumption. 
The asymmetry arises because one of the parties is assumed to enjoy persistent political advantage, which is formalized as a higher probability of winning an election. Because the two decision-makers have different de facto discount factors, interesting strategic interactions arise. In particular, the disadvantaged party is endogenously more short-sighted and thus under-saves (relative to a world in which its rival had the same effective shortsightedness), while the advantaged party is less short-sighted and thus over-saves (relative to a world in which its rival had the same effective short-sightedness). Political uncertainty is propagated throughout the economy via volatility in policies, and economic cycles endogenously arise. This is the case even though there is no source of uncertainty other than the identity of the policymaker. Welfare is lower relative to the first best not only because of a dynamic inefficiency (investment is too low), but also because volatility in macroeconomic variables (output, employment, and consumption) is introduced.

Increases in political advantage widen the gap between the policies chosen by the two parties, as well as their probabilities of being elected. Despite the fact that the size of the government (total expenditures to output) increases with the political bias, long-run average output rises. The reason is that a larger proportion of revenues is devoted to productive public investment, on average. I find that the size of cycles induced by changes in political advantage is non-monotonic because it is affected by changes in policy and probabilities in opposite directions. Economies in which the political advantage is low exhibit rapid turnover but small fluctuations in policy, as the difference in investment shares is small. This happens because both parties have similar election prospects and are thus equally short-sighted. At the other extreme, when the biases are large, so are the differences in policy. But the most popular party is in power more often, and hence, fluctuations are small. Volatility is largest for intermediate values of the political bias. Using a proxy for investment shares and electoral advantage for the US during the period 1929-2006, I show that these two variables tend to comove, providing some support for the theory.

The organization of the paper is as follows. A discussion of the existing literature is presented next. The benchmark model is described in Section 2. To make the exposition clear, the analysis is performed under the assumption of exogenous political turnover. The Markov-perfect equilibrium is defined in Section 3 and characterized in Section 4. Section 5 provides empirical support for some implications of the theory. Micro-foundations for the different election probabilities are presented in Section 6. The environment is extended to introduce a voting stage in which agents are subject to an ideological bias and, using a hybrid citizen-candidate and probabilistic voting model, election probabilities are endogenously derived. Section 7 concludes.

\section{Related Literature}

This paper contributes to the literature that analyzes the dynamic efficiency of policy choice in representative democracies. It builds on the work by Besley and Coate (1998) and Alesina and Tabellini (1990), who present the first theories of political failure. In Alesina and Tabellini (1990), parties choose to overspend on public goods and to create an excessive level of debt when the outcome of elections is uncertain. In Besley and Coate (1998) parties 
fail to undertake a public investment that is potentially Pareto improving due to a lack of commitment in a two-period model. My work extends some of their insights to a dynamic infinite-horizon political economy model, particularly relevant for assessing the long-run effects of current policy.

Amador (2008) and Azzimonti (2010) also analyze the inefficiencies generated by a common pool problem but in a fully dynamic infinite-horizon model. Their basic mechanism, like the one in this paper, is based on the trade-offs described in Alesina and Tabellini (1990). Amador finds that politicians are too impatient, behaving as hyperbolic consumers, which results in inefficient overspending and excessive deficit creation. ${ }^{1}$ In Azzimonti, overspending results in equilibrium due to political turnover but in an environment in which the government distorts private investment in order to finance group-specific public goods. Neither considers public investment. Battaglini and Coate (2007) introduce durable public goods financed by the government. Instead of focusing on political parties, they assume that policy is decided through legislative bargaining. In their paper, distortions arise due to the assumption of proportional taxation on labor income, while I assume those away by focusing on lump-sum taxes. In my paper distortions arise because public capital affects the productivity of labor, and these are completely independent in Battaglini and Coate's setup. ${ }^{2}$ These three papers restrict attention to symmetric environments so there are no fluctuations in macroeconomic variables induced by changes in power. The analysis of partisan cycles in policy and economic allocations generated by political advantage is a main contribution relative to their work.

This paper also contributes to the literature on inefficiencies resulting from the government's lack of commitment. While existing models of repeated voting find strategic interactions, most of them must rely on numerical methods to characterize the Markovperfect equilibrium (e.g. Krusell and Rios-Rull 1999 or Bachman and Bai, 2010). Hassler, Mora, Storesletten, and Zilibotti (2004), on the other hand, find analytical solutions in an overlapping generations setup in which policy is decided by majority voting, but they assume away political uncertainty. Hassler, Storesletten, and Zilibotti (2007) find that expenditures on a consumable public good can be inefficient, but in a model in which agents who live for two periods vote on a redistributive policy. Unlike in their work, governments devote part of the expenditures to productive investment in my model, which allows me to analyze the effects of policy on economic development.

I also extend existing work by endogenizing the probabilities of reelection in a dynamic setup. A key assumption in this paper is that politicians are citizen candidates who do not have a commitment to platforms. As a result, voters expect the incumbent to maximize the utility of the group he represents (disregarding the welfare of other groups). This is opposite

\footnotetext{
${ }^{1}$ Caballero and Yared (2010), Cuadra and Sapriza (2008), Debortoli and Nunes (2008, 2010), Devereux and Wen (1998), Kumhof and Yakadina (2007) and Ilzetzki (2011) also analyze environments in which exogenous political turnover introduces inefficiencies in debt accumulation and the level of taxation in Markovswitching models. See Lagunoff and Bai (2010) for an interesting case in which the probabilities of re-election are exogenous but depend on the aggregate state of the economy.

${ }^{2}$ Besley, Ilzetzki, and Persson (2010) study the effects of exogenous political instability on fiscal capacity (a durable public good) in a similar environment.
} 
to the standard result in probabilistic voting models with commitment to platforms, where the politician's maximization problem is equivalent to that of a benevolent planner (see Sleet and Yeltekin, 2008 or Farhi and Werning, 2008). In a recent paper Battaglini (2010) considers an environment in which expected ideological biases are persistent and candidates are office seekers with commitment to platforms. He finds that the political equilibrium exhibits excessive debt creation and overspending. Due to the assumption that there is no ex ante bias in favor of or against any candidate, the equilibrium is symmetric. Therefore, there are no fluctuations in debt, taxes, or macroeconomic variables generated by switches of power (other than those resulting from productivity shocks) which is the focus of this study.

Finally, this paper is related to the literature on 'partisan cycles'. In contrast to previous models in this literature (such as Milesi-Ferretti and Spolaore, 1994, Persson and Svensson, 1989 or more recently Song, 2010 and Azzimonti and Talbert, 2011), I do not need to assume exogenous differences in preferences over the size of public expenditures in order to generate fluctuations. Parties have the same ex-ante utility over the size of spending on public goods and on the level of investment. In equilibrium one party may spend more and invest less just because it loses more often as a result of an ideological disadvantage.

\section{The benchmark model}

In this section I describe the economic environment and define a competitive equilibrium given policy. Conditions satisfied by Pareto optimal allocations are presented to be used as a benchmark when discussing inefficiencies arising from political uncertainty in the following sections.

\section{$2.1 \quad$ Economic environment}

Consider an infinite-horizon economy populated by agents of equal measure who live in one of two regions, $A$ and $B$. While they have identical income and identical preferences over private consumption, they disagree on the composition of public expenditures, since public goods can be region-specific (e.g. parks, museums, environmental protection, public television, etc.). The instantaneous utility of agent $j$ in region $J$ is

$$
u\left(c_{j}, n_{j}\right)+v\left(g^{J}\right)
$$

where $c_{j}$ denotes the consumption of private goods, $n_{j}$ denotes labor, and $g^{J}$ is the level of discretionary spending on local goods in region $J$. Notice that an agent living in region $A$ derives no utility from the provision of a good in region $B$ (and vice versa). In principle there will be disagreement in the population over the desired composition of public expenditures but not on its size, since both types have the same marginal rate of substitution between private and public goods. Throughout the text, I will assume that 
preferences over consumption are of the GHH form

$$
u(c, n)=\log \left(c-\frac{n^{1+\frac{1}{\epsilon}}}{1+\epsilon}\right)
$$

where $\epsilon$ is the elasticity of labor, and preferences over the provision of public goods are logarithmic

$$
v\left(g^{J}\right)=\log \left(g^{J}+G\right) .
$$

The constant $G$ is introduced for technical reasons, in order to ensure that utility is bounded when the public good is not provided to the region, $g^{J}=0$. Agents discount the future at rate $\beta \in(0,1)$.

There are infinitely many competitive firms that produce a single consumption good and hire labor each period so as to maximize profits, which are distributed back to consumers who own shares of these firms. Firms have access to a Cobb-Douglas technology

$$
F\left(K_{g}, n\right)=A K_{g}^{\theta} n^{1-\theta},
$$

where $n$ is the aggregate labor supply and $K_{g}$ is the stock of public capital (i.e., infrastructure, public health, education, knowledge produced by the public sector's R\&D and expenditures on national defense or law enforcement). Its level is determined by government investments and acts as an externality in production. The idea behind this specification is that the better the infrastructure (roads, harbors, sewers, etc.), the more educated the population and the stronger the protection of property rights, the higher the productivity of the private sector. We assume that $K_{g}$ depreciates fully after being used in production. In equilibrium, workers are paid the wage $w$ and firms distribute profits

$$
\Pi=F\left(K_{g}, n\right)-w n
$$

as dividends to individual shareholders.

The government raises revenues via lump-sum taxes $\tau$ which are chosen every period, so private consumption is

$$
c_{j}=w n_{j}+\Pi-\tau .
$$

Taxes are used to finance the provision of consumable public goods $\left(g^{A}\right.$ and $\left.g^{B}\right)$ and investments in productive public capital $\left(K_{g}^{\prime}\right)$. The cost of producing $g>0$ units of a local public good is linear $x(g)=g+G$, with $x(0)=0$. This assumption allows us to characterize the solution analytically, but all results hold as $G \rightarrow 0$. Assuming that there is no debt, the government must balance its budget every period. Its budget constraint is

$$
x\left(g^{A}\right)+x\left(g^{B}\right)+K_{g}^{\prime}=\tau,
$$

where primes denote next period variables. The assumption of lump-sum taxes is made in order to highlight the fact that inefficiencies in production may arise due to political frictions even when the government has access to non-distortionary financing instruments. 


\subsection{Competitive equilibrium given policy}

Firms decide how much labor to hire given wages and distribute profits back in the form of dividends to agents, who own shares of these firms. Agents choose consumption and leisure, taking wages and government policy (public spending and investment) as given. A competitive equilibrium given policy is defined below (I omit the stock of public capital $K_{g}$ from all functions to simplify notation).

Definition 2.1 A competitive equilibrium given government policy $\Upsilon=\left\{g^{A}, g^{B}, K_{g}^{\prime}\right\}$ is a set of allocations, $\left\{c_{j}(\Upsilon), n_{j}(\Upsilon), \Pi(\Upsilon)\right\}$, prices $w(\Upsilon)$, and taxes $\tau(\Upsilon)$ such that:

(i). Agents maximize utility subject to their budget constraint. Agent j's labor supply satisfies

$$
u_{1}\left(c_{j}(\Upsilon), n_{j}(\Upsilon)\right) w(\Upsilon)+u_{2}\left(c_{j}(\Upsilon), n_{j}(\Upsilon)\right)=0,
$$

where

$$
c_{j}(\Upsilon)=w(\Upsilon) n_{j}(\Upsilon)+\Pi(\Upsilon)-\tau(\Upsilon) .
$$

(ii). Firms maximize profits, so $w(\Upsilon)=F_{2}\left(K_{g}, n(\Upsilon)\right)$ and $\Pi(\Upsilon)=F\left(K_{g}, n(\Upsilon)\right)-w(\Upsilon) n(\Upsilon)$.

(iii). Markets clear $n(\Upsilon)=\int_{j} n_{j}(\Upsilon)$.

(iv). The government budget constraint is satisfied.

$$
\tau(\Upsilon)=x\left(g^{A}\right)+x\left(g^{B}\right)+K_{g}^{\prime}
$$

The static nature of firms' and workers' economic decisions simplifies the characterization of the competitive equilibrium to a great extent. Moreover, from condition (i) we can see that agents' decisions are independent of their type $j$, which results from the additive separability of the utility derived from the provision of public goods. Hence, there is aggregation and we can think of the competitive equilibrium as characterized by the decisions of a representative agent with $n_{j}(\Upsilon)=n(\Upsilon)$ and $c_{j}(\Upsilon)=c(\Upsilon) .^{3}$

Replacing the firm's optimal decisions and the government budget constraint into the agent's budget constraint we obtain consumption as a function of policy,

$$
c(\Upsilon)=F\left(K_{g}, n(\Upsilon)\right)-x\left(g^{A}\right)-x\left(g^{B}\right)-K_{g}^{\prime},
$$

with aggregate labor $n(\Upsilon)$ satisfying

$$
u_{1}(c(\Upsilon), n(\Upsilon)) F_{2}\left(K_{g}, n(\Upsilon)\right)+u_{2}(c(\Upsilon), n(\Upsilon))=0
$$

\footnotetext{
${ }^{3}$ This result holds for any pair of concave functions $u(c, n)$ and $v(g)$, not just the particular ones assumed in the text.
} 


\subsection{Planning solutions}

Before describing the outcome under political competition (where different parties alternate in power), it is useful to characterize the optimal allocation chosen by a benevolent social planner. The planner chooses $\left\{c, n, K_{g}^{\prime}, g^{A}, g^{B}\right\}$ so as to maximize a weighted sum of utilities, where the weight on type $J$ agents is $\lambda^{J} \in[0,1]$ (with $\lambda^{A}+\lambda^{B}=1$ ). The planner's maximization problem is

$$
V^{*}\left(K_{g}\right)=\max \sum_{J=A, B} \lambda^{J}\left[u(c, n)+v\left(g^{J}\right)\right]+\beta V^{*}\left(K_{g}^{\prime}\right),
$$

subject to the resource constraint:

$$
c+x\left(g^{A}\right)+x\left(g^{B}\right)+K_{g}^{\prime}=F\left(K_{g}, n\right) .
$$

As long as the planner gives a positive weight to each agent, the optimal allocation of public good $J$ will be such that its marginal utility is proportional to the marginal utility of private consumption. ${ }^{4}$

Departures from this condition represent a wedge $\Delta_{g}$ in the optimal provision of $g^{J}$

$$
\Delta_{g}=-u_{1}(c, n) x_{g}\left(g^{J}\right)+\lambda^{J} v_{g}\left(g^{J}\right) .
$$

By varying $\lambda^{J}$ between 0 and 1 it is possible to trace the Pareto frontier that characterizes the optimal provision of public goods. Concavity of $v$ implies that if type $A$ agents have a higher weight in the social welfare function, more of their desired public good will be provided (at the expense of type $B$ agents).

The second optimality condition refers to the optimal labor supply. Under this condition, the planner equates the marginal disutility of working to the marginal increase in the utility of consumption generated by additional production. Departures from this equation define a labor wedge

$$
\Delta_{n}=u_{1}(c, n) F_{2}\left(K_{g}, n\right)-u_{2}(c, n) .
$$

Finally, the planner chooses the level of public capital that equates the marginal costs in terms of foregone consumption to the discounted marginal benefits of investment. Departures from this condition define an investment wedge

$$
\Delta_{k}=-u_{1}(c, n)+\beta u_{1}\left(c^{\prime}, n^{\prime}\right) F_{1}\left(K_{g}^{\prime}, n^{\prime}\right) .
$$

The planner's Euler equation is completely independent of the choice of the social welfare function: Changes in $\lambda^{J}$ do not affect this margin. The result follows from assuming that both agents have the same trade-off between private and public consumption (i.e., $u$ and $v$ are equal for all agents). ${ }^{5}$

\footnotetext{
${ }^{4}$ If the planner only cares about the well-being of, say, agent $A$, it will set $g_{t}^{B}=0 \forall t$ and $g_{t}^{A}$ so as to equate the marginal rate of substitution between private and public goods to the marginal cost of providing the goods $x_{g}(g)$.

${ }^{5}$ It is important to note that the planner is constrained to offer all households the same consumption allocation (that is, $c^{A}=c^{B}$ ). This condition is imposed in order to capture the constraint faced by the government in the political equilibrium (where parties cannot tax agents at different rates).
} 


\section{Politico-economic equilibrium}

The role of the government in this economy is to provide public goods and productive public capital. Given the disagreement between groups over which public good should be provided, political parties will endogenously arise in a democratic environment. I analyze a stylized case in which there are two parties, $A$ and $B$, representing each group in the population and competing for office every period. They alternate in power according to an exogenous election probability $p_{i}, i \in\{A, B\}$. The asymmetry arises because one of the groups has greater political power than the other. In particular, I assume that type-B candidates are more likely to be elected

$$
p_{B}=0.5+\xi, \text { with } \xi \in\left[0, \frac{1}{2}\right],
$$

and $p_{A}=0.5-\xi$. We can interpret $\xi$ as measuring B's political advantage.

The elected party chooses the tax rate and the allocation of government resources between the different types of spending and investment so as to maximize the utility of its own type. ${ }^{6}$

\subsection{Markov-perfect equilibrium}

There is no commitment technology, so promises made by any party before elections are not credible unless they are optimal ex-post. The party in power plays a game against the opposition taking their policy as given. Alternative realizations of history (defined by the sequence of policies up to time $t$ ) may result in different current policies. In principle, this dynamic game allows for multiple subgame-perfect equilibria that can be constructed using reputation mechanisms. I will rule out such mechanisms and focus instead on Markovperfect equilibria (MPE), defined as a set of strategies that depend only on the currentpayoff relevant - state of the economy. Given the sequence of events the only payoff-relevant state variable besides the identity of the party in power is the stock of public capital. In a Markov-perfect equilibrium, policy rules are functions of this state.

The equilibrium objects we are interested in are policy functions, allocations, and value functions. There are three policy functions: The investment rule of incumbent $i, h_{i}\left(K_{g}\right)$, and expenditures in each region-specific good $g_{i}^{A}\left(K_{g}\right)$ and $g_{i}^{B}\left(K_{g}\right)$. The labor supply $n_{i}\left(K_{g}\right)$ and consumption $c_{i}\left(K_{g}\right)$ under incumbent $i$ 's policies summarize the allocations. The value function of agent type $J$ when his group is in power will be denoted by $V_{J}\left(K_{g}\right)$ and when his group is out of power by $W_{J}\left(K_{g}\right)$.

The incumbent must decide on the optimal policy, knowing that he will be replaced by a different policymaker with probability $p_{i}$. Suppose that $B$ is the elected party. Given the stock of public capital $K_{g}$, his objective function today is:

\footnotetext{
${ }^{6}$ In that sense this is a partisan model. A politician from party $j$ is just like any other agent in that group, so he wants to maximize his type's utility. In contrast, other models in the literature assume that politicians can extract rents from being in power, so their objective is to maximize the probability of winning the next election. See Drazen (2000) or Persson and Tabellini (2000) for a discussion of opportunistic models.
} 


$$
\max _{g^{A}, g^{B}, K_{g}^{\prime} \geq 0} u(c, n)+v\left(g^{B}\right)+\beta\left\{p_{B} V_{B}\left(K_{g}^{\prime}\right)+p_{A} W_{B}\left(K_{g}^{\prime}\right)\right\}
$$

where consumption and labor satisfy equations (2) and (3).

Since $g^{A}$ and $g^{B}$ affect only today's utility, tomorrow's decisions are independent of the composition of expenditures. If party $i$ is in power, it will choose $g_{i}^{J}=0$, for $J \neq i$, which further simplifies the problem. Slightly abusing notation, we use $g_{i}\left(K_{g}\right)$ to denote the equilibrium amount spent by incumbent $i$ on the local public good $i$. The description of the problem is completed by defining the functions $V_{B}\left(K_{g}\right)$ and $W_{B}\left(K_{g}\right)$ :

$$
V_{B}\left(K_{g}\right)=u\left(c_{B}\left(K_{g}\right), n_{B}\left(K_{g}\right)\right)+v\left(g_{B}\left(K_{g}\right)\right)+\beta\left\{p_{B} V_{B}\left(h_{B}\left(K_{g}\right)\right)+p_{A} W_{B}\left(h_{B}\left(K_{g}\right)\right)\right\}
$$

and

$$
W_{B}\left(K_{g}\right)=u\left(c_{A}\left(K_{g}\right), n_{A}\left(K_{g}\right)\right)+\beta\left\{p_{B} V_{B}\left(h_{A}\left(K_{g}\right)\right)+p_{A} W_{B}\left(h_{A}\left(K_{g}\right)\right)\right\},
$$

where $\Upsilon_{i}\left(K_{g}\right)=\left\{g_{i}^{A}\left(K_{g}\right), g_{i}^{B}\left(K_{g}\right), h_{i}\left(K_{g}\right)\right\}$ denotes the equilibrium policy functions chosen by incumbent type $i$, and where $c_{i}\left(K_{g}\right)=c\left(\Upsilon_{i}\left(K_{g}\right)\right)$ and $n_{i}\left(K_{g}\right)=n\left(\Upsilon_{i}\left(K_{g}\right)\right)$ are the competitive equilibrium values of consumption and labor under the political equilibrium policies.

We can now define a Markov-perfect equilibrium, which just imposes consistency between private agents and the government's decisions.

Definition 3.1 A Markov-perfect equilibrium with exogenous political turnover is a set of value and policy functions such that:

i. Given the re-election probabilities and $C E$ allocations and prices, the functions $h_{i}\left(K_{g}\right)$, $g_{i}^{B}\left(K_{g}\right), g_{i}^{A}\left(K_{g}\right), V_{i}\left(K_{g}\right)$, and $W_{i}\left(K_{g}\right)$ solve incumbent $i^{\prime}$ s maximization problem, ( 7$)$, (8), and (9).

ii. Given the re-election probabilities and government policy, the functions $c_{i}\left(K_{g}\right)$ and $n_{i}\left(K_{g}\right)$ satisfy equations (2) and (3).

\subsection{Differentiable Markov-perfect equilibrium (DMPE)}

In order to further characterize the trade-offs faced by an incumbent when choosing investment, I will focus on differentiable policy functions. Klein, Krusell, and Rios-Rull (2008) made this assumption (in a different context), arguing that there could be in principle an infinitely large number of Markov equilibria. By assuming differentiability, the problem delivers a solution that is the limit to the finite-horizon problem. Moreover, it allows us to derive the government optimality condition even though the envelope theorem doesn't hold. 
The choice of expenditures is a static one, affecting only the intratemporal margin. At the optimum, the government chooses $g$ so that the marginal cost of providing the good in terms of consumption equals its marginal benefit:

$$
u_{1}\left(c_{B}\left(K_{g}\right), n_{B}\left(K_{g}\right)\right) x_{g}(g)=v_{g}(g) .
$$

We can see that government spending in the MPE is sub-optimal from the standpoint of a social planner-which gave positive weight to both types - since $\Delta_{g} \neq 0$ (see eq. 4 ). Sub-optimality arises for two reasons. First, the group out of power gets no provision of their preferred good. Second, there is overspending in the sense that the marginal rate of private consumption is too low when compared to that of the utilitarian optimum (or any level associated with positive weights $\lambda^{J}>0$. Even the group in power would prefer a lower level of $g$ if the difference was invested in productive capital and subsequently used in the provision of its preferred good instead.

The investment decision affects the intertemporal margin; the costs of increasing public capital are paid today, while the benefits are received in the future. The government chooses $K_{g}^{\prime}$ so that the marginal cost in terms of foregone consumption equals expected marginal benefits:

$$
u_{1}\left(c_{B}\left(K_{g}\right), n_{B}\left(K_{g}\right)\right)=\beta\left\{p_{B} V_{B 1}\left(K_{g}^{\prime}\right)+p_{A} W_{B 1}\left(K_{g}^{\prime}\right)\right\}
$$

As in the planner's first-order condition, the cost of an extra unit of investment in public capital is given by a reduction in current utility via a decrease in consumption $-u_{1}(c, n)$. The benefits, on the other hand, now depend on the identity of the party that wins the next election. When $K_{g}^{\prime}$ increases, expected future utility rises from the expansion of resources. Type $B$ agents enjoy an increase of $V_{B 1}\left(K_{g}\right)=\frac{\partial V_{B}\left(K_{g}^{\prime}\right)}{\partial K_{g}^{\prime}}$ utils if they win the next election (which occurs with probability $p_{B}$ ) and $W_{B 1}\left(K_{g}\right)=\frac{\partial W_{B}\left(K_{g}^{\prime}\right)}{\partial K_{g}^{\prime}}$ otherwise (which occurs with probability $\left.p_{A}=1-p_{B}\right)$.

The politico-economic equilibrium studied here implies several distortions relative to the first best as shown in Proposition 3.1.

Proposition 3.1 The investment wedge in incumbent B's first-order condition is given by

$$
\Delta_{k}=\beta p_{A}\{D E+M B+I D\}
$$

where

$$
\begin{aligned}
& M B=u_{1}\left(c_{A}\left(K_{g}^{\prime}\right), n_{A}\left(K_{g}^{\prime}\right)\right) F_{1}\left(K_{g}^{\prime}, n_{A}\left(K_{g}^{\prime}\right)\right)-u_{1}\left(c_{B}\left(K_{g}^{\prime}\right), n_{B}\left(K_{g}^{\prime}\right)\right) F_{1}\left(K_{g}^{\prime}, n_{B}\left(K_{g}^{\prime}\right)\right) \\
& D E=-x_{g}\left(g_{A}\left(K_{g}^{\prime}\right)\right) g_{A 1}\left(K_{g}^{\prime}\right) u_{1}\left(c_{A}\left(K_{g}^{\prime}\right), n_{A}\left(K_{g}^{\prime}\right)\right), \\
& I D=h_{A 1}\left(K_{g}^{\prime}\right)\left[-u_{1}\left(c_{A}\left(K_{g}^{\prime}\right), n_{A}\left(K_{g}^{\prime}\right)\right)+u_{1}\left(c_{A}\left(\tilde{K}_{g}^{\prime}\right), n_{A}\left(\tilde{K}_{g}^{\prime}\right)\right)\right], \text { where } \tilde{K}_{g}^{\prime}=h_{B}^{-1}\left(h_{A}\left(K_{g}^{\prime}\right)\right) .
\end{aligned}
$$

Proof See Appendix 8.1. 
If $p_{A}=0, B$ would remain in office forever. In such a case, the incumbent would invest exactly as a benevolent planner and the investment wedge would be zero. This cannot be interpreted as implying that allocations are equivalent, because $g^{A}=0$. Growth implications are the same (since efficiency is achieved), but at the expense of some proportion of the population enjoying lower utility as one type of public good is never provided.

When $p_{A}>0$, there is a positive likelihood $\left(1-p_{B}\right)$ that the group in office loses power next period, which introduces a wedge in the investment optimality condition. This wedge is composed of three terms.

The first term, $D E$, captures the cost of disagreement in terms of the provision of public goods. When the incumbent is not re-elected (which happens with probability $p_{A}$ ), a marginal increase on public capital today changes the opposition's spending in public goods tomorrow by $g_{A 1}\left(K_{g}^{\prime}\right)$. This results in a cost in terms of foregone consumption next period with no utility benefit, since the incumbent derives no utility from that public good. From today's perspective it is optimal, then, to decrease investment with respect to the certainty case: The current incumbent wants to 'tie the hands' of its successor in order to restrict its spending. The disagreement over the composition of public goods, together with the political uncertainty, deters public investment. ${ }^{7}$

If parties had the same political power $\left(p_{A}=p_{B}\right)$, the composition of expenditures would be the only source of disagreement. The center of the conflict would be what to spend the budget on, instead of how much to spend (as analyzed in detail in Azzimonti, 2010). All distortions would be summarized by the $D E$. Under asymmetry, there is also disagreement on the levels of spending and investment, as seen from the two additional effects described next.

Because parties' constituencies differ, the reaction of the opposition to a change in $K_{g}^{\prime}$ will be sub-optimal from the standpoint of party $B$ (since both groups value the future differently). The second term, $M B$, corresponds to the difference in the marginal benefit of investment received when tomorrow's government policy is chosen by the opposition and the one obtained if party $B$ remained in power.

The last term in the optimality condition, $I D$, captures the investment disagreement resulting from the fact that parties would invest differently if in power. Because $B$ 's likelihood of staying in power is larger, the expected marginal benefits of investing one more dollar in public capital are higher than for party $A$, which would increase investment next period only by $h_{A k}\left(K_{g}^{\prime}\right)$. This distorts future investment costs differentially for both parties, introducing an additional distortion.

Since specific functional forms for utility and production were not used to derive equation 11, this equation describes more generally the optimal behavior of an incumbent in a political equilibrium with re-election uncertainty.

\footnotetext{
${ }^{7}$ This effect is similar to that observed in Persson and Svensson (1989). Besley and Coate (1998) find that disagreements over redistribution policies can result in inefficient levels of investment. Milesi-Ferretti and Spolaore (1994) also obtain strategic manipulation but for an alternative environment. For an infinitehorizon economy with symmetric shocks that also exhibits a disagreement effect, see Azzimonti (2010).
} 


\section{Characterization}

It is instructive to analyze the Pareto optimal allocations first, obtained by solving the planner's problem presented in Section 2.3. Under the assumptions above, the economy collapses to a traditional neoclassical economy and thus the standard results apply. There exists a unique equilibrium in which the labor supply takes a simple form,

$$
n\left(K_{g}\right)=\left[\epsilon A(1-\theta) K_{g}^{\theta}\right]^{\frac{\epsilon}{1+\epsilon \theta}},
$$

and the level of production is given by

$$
F\left(K_{g}, n\left(K_{g}\right)\right)=\bar{A} K_{g}^{\bar{\theta}} \quad \text { where } \quad \bar{A}=A[\epsilon A(1-\theta)]^{\frac{\epsilon(1-\theta)}{1+\epsilon \theta}} \quad \text { and } \quad \bar{\theta}=\frac{\theta(1+\epsilon)}{1+\epsilon \theta} .
$$

Public capital evolves according to

$$
K_{g}^{\prime}=s^{*} \tilde{A} K_{g}^{\bar{\theta}}, \quad \text { with } \quad \tilde{A}=\bar{A}-\frac{[\epsilon A(1-\theta)]^{\frac{1+\epsilon}{1+\epsilon \theta}}}{1+\epsilon},
$$

where $\tilde{A} K_{g}^{\bar{\theta}}$ equals the total amount of resources net of the disutility of labor, and we can think of it as 'labor-adjusted' production. A benevolent planner invests a constant proportion $s^{*}=\beta \bar{\theta}$ of labor-adjusted resources, independently of the Pareto weights attached to each group (these weights affect the composition of region-specific public goods but not the total amount of resources devoted to them). Since $\bar{\theta}<1$, public capital converges deterministically to a steady-state level $K_{g}^{*}=[\beta \bar{\theta} \tilde{A}]^{\frac{1}{1-\bar{\theta}}}$.

\subsection{Dynamic inefficiencies in the MPE}

The competitive equilibrium given policy determines consumption and labor as functions of government spending and investment. Because taxes are lump sum and there are no income effects under the GHH formulation, the labor supply follows eq. (12). Consumption satisfies

$$
c_{i}\left(K_{g}\right)=\bar{A} K_{g}^{\bar{\theta}}-g_{i}\left(K_{g}\right)-G-h_{i}\left(K_{g}\right) .
$$

Proposition 4.1 fully characterizes government policy.

Proposition 4.1 There exists a differentiable Markov equilibrium where incumbent $i$ chooses:

$$
g_{i}\left(K_{g}\right)=\frac{1}{2}\left(1-s_{i}\right) \tilde{A} K_{g}^{\bar{\theta}}-G, \quad h_{i}\left(K_{g}\right)=s_{i} \tilde{A} K_{g}^{\bar{\theta}}, \quad \text { and } \quad \tau_{i}=\frac{1}{2}\left(1+s_{i}\right) \tilde{A} K_{g}^{\bar{\theta}}
$$

and the propensity $s_{i}$ satisfies

$$
s_{i}=\bar{\theta} \beta\left[\frac{1+p_{i}}{2-\bar{\theta} \beta\left(1-p_{i}\right)}\right] .
$$

Proof See Appendix 8.2. 
An incumbent of type $i$ invests a constant proportion of labor-adjusted resources, with the propensity to invest being an increasing function of the probability of reelection. Differentiation of equation 21 yields

$$
\frac{\partial s_{i}}{\partial p_{i}}=\frac{2 \bar{\theta} \beta(1-\bar{\theta} \beta)}{\left(2-\bar{\theta} \beta\left(1-p_{i}\right)\right)^{2}}>0 .
$$

The benefits from an extra unit of investment are not fully internalized, which causes the incumbent to behave myopically and overspend today on unproductive public goods (and underinvest in public capital). The effect is stronger, the lower the probability of remaining in power. The next corollary summarizes the distortionary effects of political uncertainty on government policy.

Corollary 4.1 The Markov-perfect equilibrium is Pareto efficient if and only if $p_{i}=1$. When $p_{i}<1$ there is underinvestment in public capital $s_{i}<s^{*}$, so the MPE is inefficient.

Proof Let $p_{i}=1$, then $s_{i}=s^{*}$ from eq. (21). Let $p_{i}<1$, then $s_{i}<s^{*}$ by eq. (14).

The intuition behind this result can be understood by looking at the trade-offs faced by the group in power. An incumbent who believes that he will be replaced with high probability does not have strong incentives to abstain from consumption today in order to invest in public capital. Knowing that it is very likely that tomorrow's policymaker would prefer a different composition of spending, the incumbent tries to manipulate next period's policy through the choice of the state variable. He ties the hands of his successor by decreasing the amount of available resources (i.e., investing a small amount today), which shrinks the tax base tomorrow. It is then reasonable to expect the propensity to invest under political uncertainty to be lower than that chosen by a planner. Finally, note that while the equilibrium is Pareto optimal when $p_{i}=1$, the allocations do not coincide with those chosen under a utilitarian planner because one of the groups never receives its preferred public good.

\subsection{Ideology-driven economic fluctuations}

An interesting feature of this model is that it delivers endogenous cycles in economic variables generated by parties' alternation of power. Even though there are no exogenous productivity shocks, output, investment, consumption, labor, and taxes fluctuate in the long run.

From the government's maximization problem, the evolution of public capital follows

$$
K_{g}^{\prime}=s_{i} \tilde{A} K_{g}^{\bar{\theta}}
$$

where $s_{i} \in\left\{s_{A}, s_{B}\right\}$ depends on the identity of the incumbent. Since $p_{B}>0.5$, eq. 21 implies

$$
s_{A}<s_{B} .
$$

Consider an economy with $0<K_{g 0}<K_{g A}^{s s}$. If party $i$ were in power long enough, capital would converge to the steady-state value $K_{g i}^{s s}$, as shown in the following lemma. 
Lemma 4.1 Fix $i$, let $p_{i}=1$ and $K_{g 0}>0 \Rightarrow \exists$ a unique stationary point $h_{i}\left(K_{g i}^{s s}\right)=K_{g i}^{s s}$ given by $K_{g i}^{s s}=\left(s_{i} \tilde{A}\right)^{\frac{1}{1-\theta}}$.

Proof Existence is trivial from $h_{i}\left(K_{g}\right)=s_{i} \tilde{A} K_{g}^{\bar{\theta}}$. Uniqueness follows from the properties of the policy function: (i) it is strictly increasing, $h_{i}^{\prime}\left(K_{g}\right)=s_{i} \tilde{A} \bar{\theta} K_{g}^{\bar{\theta}-1}>0$ since $s_{i} \in[0,1]$ and $\bar{\theta}<1$, (ii) strictly concave $h_{i}^{\prime \prime}\left(K_{g}\right)=s_{i}(\bar{\theta}-1) \tilde{A} \bar{\theta} K_{g}^{\bar{\theta}-2}<0$, and (iii) it crosses the $45^{\circ}$ line from above $h_{i}^{\prime}\left(K_{g i}^{s s}\right)=\bar{\theta}<1$.

Suppose that the government always followed $B$ 's optimal investment rule. Then $K_{g}$ would evolve according to the upper line in Figure 1, converging eventually to $K_{g B}^{s s}$ (where $B$ 's policy function intersects the $45^{\circ}$ line). If $A$ 's rule was followed instead, not only would the steady state be lower $\left(K_{g A}^{s s}<K_{g B}^{s s}\right)$ but convergence would take place at a slower pace. This follows from the fact that the speed of convergence under B is larger, $h_{B}^{\prime}\left(K_{g}\right)>h_{A}^{\prime}\left(K_{g}\right)$. When parties alternate in power, public investment fluctuates following the political cycle and the evolution of capital is stochastic. A possible path is represented by the arrows in Figure 1.

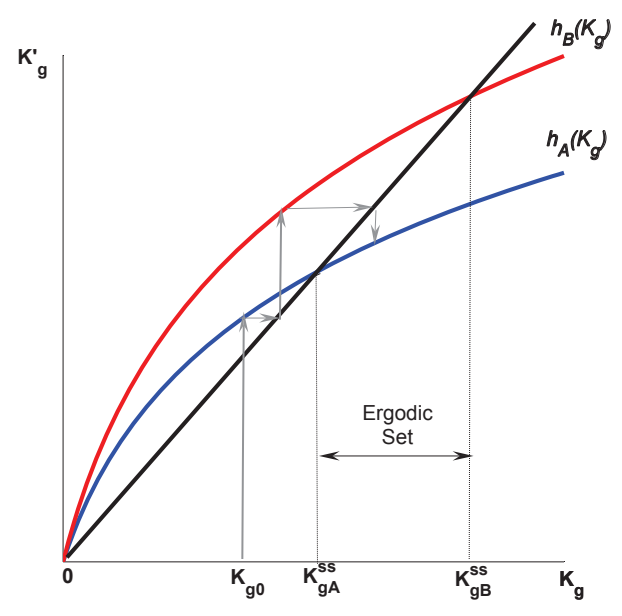

Figure 1: Evolution of capital: Policy functions

Eventually, the economy reaches an 'ergodic set' in which public capital only takes values belonging to the interval $\left[K_{g A}^{s s}, K_{g B}^{s s}\right]$. Since public capital affects the productivity of the private sector, other macroeconomic variables (such as labor, output, and consumption) also fluctuate, with political shocks propagating into the real economy. The following proposition formally characterizes the evolution of capital over time.

Proposition 4.2 Let $0<K_{g 0}<K_{g A}^{s s}$. Then $\exists T<\infty$ such that $\left\{K_{g t}\right\}_{t=0}^{T}$ is an increasing sequence and $\left\{K_{g t}\right\}_{t=T}^{\infty} \in\left[K_{g A}^{s s}, K_{g B}^{s s}\right]$. 
Proof See Appendix 8.3

The proposition states that starting from a value of capital outside of the ergodic set, the sequence of $K_{g t}$ is increasing and reaches the set in finite time. This is illustrated in Figure 2, which plots a series of investment for a simulation of this economy (the parameters used in this numerical example are described in detail in Appendix 8.10.1). It also shows the evolution of capital that would be followed by a benevolent planner. We can see that a planner reaches a significantly higher steady state as described in Corollary 4.1.

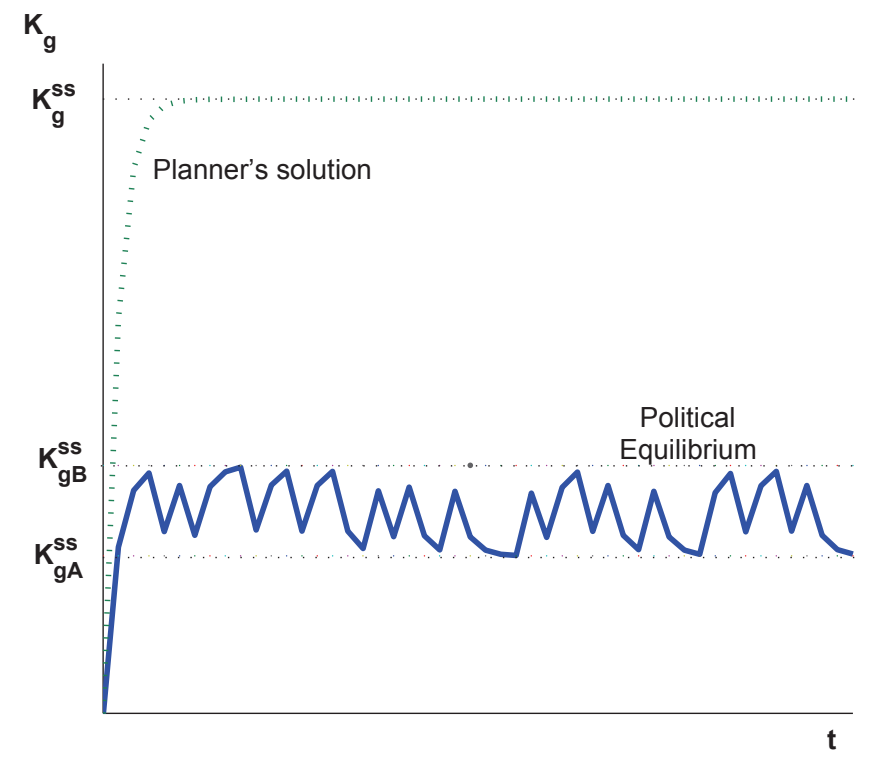

Figure 2: Evolution of capital: Simulation

Public capital exhibits an increasing trend until it reaches the ergodic set at which point it fluctuates around a constant mean. It is possible to show theoretically that this process is in general stationary. In order to do so, it is useful to work with the logarithm of our variables of interest. Let $\hat{x} \equiv \log (x)$, we can show:

Lemma 4.2 Define $\bar{\epsilon}=p_{A} \hat{s}_{A}+p_{B} \hat{s}_{B}$. Then $\hat{K}_{g t+1}$ follows an $A R(1)$ process,

$$
\hat{K}_{g t+1}=q+\bar{\theta} \hat{K}_{g t}+\epsilon_{t}
$$

where $\epsilon_{t}=\hat{s}_{t}-\bar{\epsilon}$ and $q=\log (\tilde{A})+\bar{\epsilon}$. The shocks $\epsilon_{t}$ are i.i.d and white noise with zero mean and variance

$$
\sigma^{2}=p_{A} p_{B}\left(\hat{s}_{A}-\hat{s}_{B}\right)^{2}
$$

The long-run distribution of $\hat{K}_{g t+1}$ has the following properties. 
$i$. The mean is

$$
E\left(\hat{K}_{g t+1}\right)=\frac{q}{1-\bar{\theta}} \equiv \mu .
$$

ii. The variance is

$$
\operatorname{Var}\left(\hat{K}_{g t+1}\right)=\frac{\sigma^{2}}{1-\bar{\theta}^{2}} \equiv \gamma_{0}
$$

iii. The auto-covariances and auto-correlations satisfy

$$
\operatorname{Cov}\left(\hat{K}_{g t+1}, \hat{K}_{g t+1-j}\right)=\frac{\bar{\theta}^{j}}{1-\bar{\theta}^{2}} \sigma^{2} \equiv \gamma_{j} \quad \text { and } \quad \rho_{j}=\frac{\gamma_{j}}{\gamma_{0}} .
$$

Proof Take logs in equation (15) to obtain $\hat{K}_{g t+1}=\log \tilde{A}+\bar{\theta} \hat{K}_{g t}+\hat{s}_{t}$. Since $\hat{s}_{t}$ is a twostate iid stochastic process that equals $\hat{s}_{i}$ with probability $p_{i}$, its expected value is $E\left(\hat{s}_{t}\right)=$ $p_{A} \hat{s}_{A}+p_{B} \hat{s}_{B}=\bar{\epsilon}$. By adding and subtracting $\bar{\epsilon}$ from the equation, its transformed error term $\epsilon_{t}$ has a zero mean. The variance is obtained by computing $\operatorname{Var}\left(\epsilon_{t}\right)=E\left(\epsilon_{t}^{2}\right)-\left[E\left(\epsilon_{t}\right)\right]^{2}$ and using the fact that $p_{A}=1-p_{B}$. Stationarity follows from the fact that $\bar{\theta}<1$. For the computation of long-run moments, see Hamilton (1994).

Figure 3 depicts the evolution of investment and spending in region-specific goods for a period of time, once the economy has reached its ergodic set.

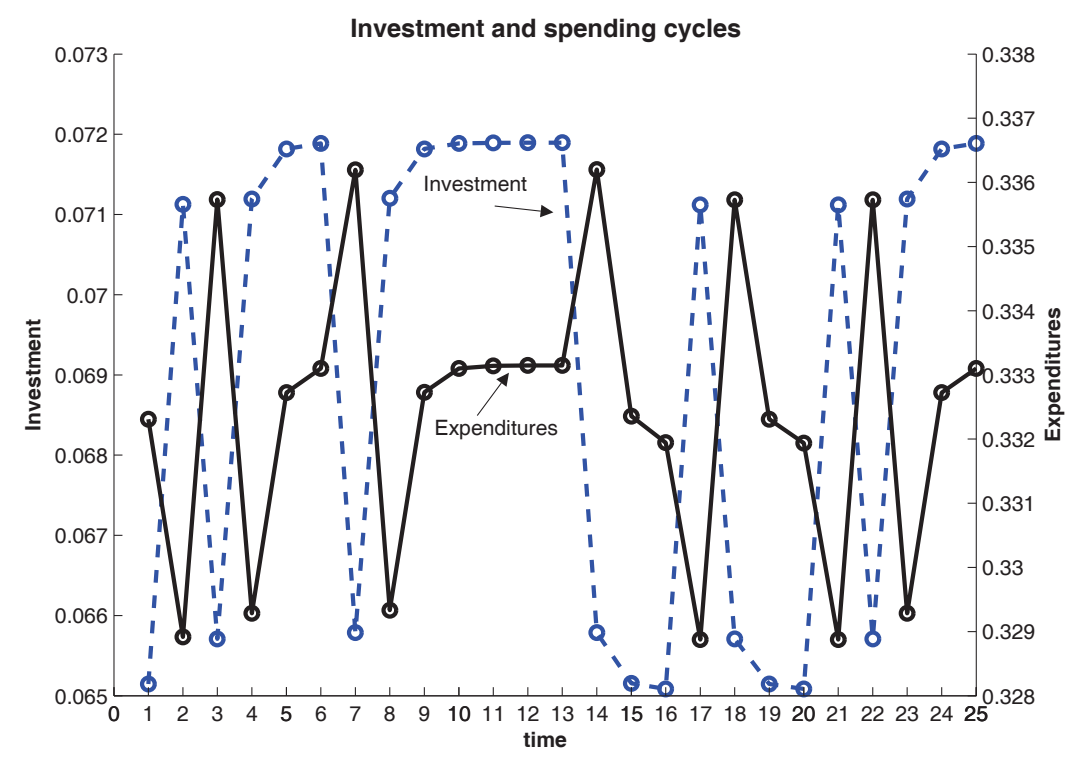

Figure 3: Understanding the cycle

The economy experiences booms when $B$ is in office and short periods of recession after party $A$ wins an election. For example, consider what happens after $\mathrm{t}=7$, when group $B$ 
takes office. There is an immediate jump in investment and a contraction of spending on public goods. This results in larger levels of public capital and hence more production (i.e., a 'boom' in the economy). Government investment grows over time (periods 7 to 13), and as public capital becomes larger, the amount provided of the public good also increases. Group $A$ gets into power in period 14, at which time expenditures on public goods have a boost accompanied by a contraction in investment. An empirical implication from this analysis is that we should observe a jump in public consumption when a party that doesn't often win takes power, together with a sudden decrease in investment. Total expenditures increase when the party with higher political power is in office, since

$$
e_{i t}=x\left(g_{i t}\right)+h_{i}\left(K_{g t}\right)=\frac{1}{2}\left(1+s_{i}\right) \tilde{A} K_{g t}^{\bar{\theta}}
$$

rises right after $B$ takes control of the government.

Notice that the nature of the economic cycle is intrinsically different from the one found in traditional partisan cycle models, in which one of the parties is assumed to derive higher utility from public goods than the other. In such models, switches in power that are associated with increases in total expenditures should also result in higher public consumption. In this model, however, increases in total spending right after a switch in government would be associated with decreases in public consumption. This implication would allow us to test the two competing theories using cross-country data (or data for US states).

Because output, consumption, and expenditures are proportional to capital, their processes are also stationary. The following lemma provides some insights into the propagation mechanism of political shocks.

\section{Lemma 4.3}

$$
\begin{gathered}
\operatorname{Var}\left(\hat{n}_{t}\right)<\operatorname{Var}\left(\hat{y}_{t}\right)<\operatorname{Var}\left(\hat{K}_{g t+1}\right) \quad \text { and } \\
\operatorname{Var}\left(\hat{c}_{t}\right)=\operatorname{Var}\left(\hat{x}\left(g_{t}\right)\right)>\operatorname{Var}\left(\hat{y}_{t}\right) .
\end{gathered}
$$

Proof See Appendix 8.4.

Switches of power cause policy changes (taxes, spending and investment), which in turn induce fluctuations in macroeconomic variables in an environment that would otherwise be deterministic. Private consumption reacts immediately to the change in taxes that occurs after a political switch. The labor supply, on the other hand, is unaffected by the resulting income effects due to the GHH preference assumption. Since the current stock of capital is fixed, output does not change either. This implies that consumption variability is larger than output variability in this model. Public consumption reacts in the same way to shocks than private consumption as a result of separability and the fact that both are assumed to have the same intertemporal elasticity of substitution. Power switches also affect investment, and this creates changes in output and labor, but with a lag. Hence, investment is more volatile than these two variables, as shown in the lemma above. It is worth mentioning at this point that since we are abstracting from productivity shocks, these implications are not to be taken as general results regarding relative volatilities but instead as illustrating 
how economic variables react to medium-term political shocks associated with switches in the ideology of the policymaker.

Lemma 4.4 Government policy and allocations are procyclical

$$
0<\operatorname{Corr}(\hat{x}(g), \hat{y})=\operatorname{Corr}(\hat{c}, \hat{y})<\operatorname{Corr}(\hat{n}, \hat{y})=1 \quad \text { and } \quad \operatorname{Corr}\left(\hat{I}_{g}, \hat{y}\right)>0 .
$$

Proof See Appendix 8.5.

Private and public consumption are less correlated with output than the labor supply. ${ }^{8}$ It is not possible to establish theoretically whether private investment is more correlated to output than consumption is, but this has been verified in our numerical example (details upon request). The reason is that investment is proportional to output but it exhibits a much higher variability.

\subsection{The effect of political power}

The probability of party $B$ 's re-election increases when its political power $\xi$ rises. If the incumbent belongs to that group, he is more likely to be succeeded by a candidate of his own type and has incentives to invest more resources in productive activities (see equation 14). If $A$ was in power instead, a higher value of $\xi$ would decrease this party's probability of staying in power. So the short-sightedness would be strengthened, resulting in a propensity to invest even further away from the first best. Despite the decrease in $A$ 's propensity to invest, long-run capital increases as B's political power goes up, as shown in Lemma 4.5.

Lemma 4.5 The long-run average of the capital stock increases with political advantage

$$
\frac{\partial E\left(\hat{K}_{g}\right)}{\partial \xi}>0
$$

Proof See Appendix 8.6.

Because $\hat{y}$ and $\hat{n}$ are increasing functions of $\hat{K}_{g}$, output and the labor supply will also increase in the long run as $\xi$ increases.

This model also provides implications for the relationship between political stability and the size of governments. The degree of political stability is closely related to the variable $\xi$. Political turnover is highest when $\xi=0$, since each party's probability of winning an election equals 0.5 . As $B$ 's advantage increases, power switches become more infrequent, and political stability goes up. The size of governments is usually measured as the ratio of total government expenditures to GDP in the empirical literature, which given our assumptions equals

$$
\frac{e_{i}}{y}=\frac{1}{2}\left(1+s_{i}\right)
$$

\footnotetext{
${ }^{8}$ Bachman and Bai (2010) also find that government consumption is procyclical in a political economy model, but their channel arises from the correlation between political wealth bias and productivity shocks.
} 
The long-run average of this variable is just $E(e / y)=p_{A} e_{A}+p_{B} e_{B}$, and can be shown to be increasing in $\xi$ following steps similar to those in Appendix 8.6 (proof available upon request). Hence, the model predicts that countries with larger political advantage - and low political turnover - should exhibit overall larger governments. Finally, long-run public consumption as a fraction of output is decreasing in this variable, since $E\left(\frac{x(g)}{y}\right)=\frac{1}{2}-E(e / y)$. More concicely, as the advantage of $B$ increases, a larger percentage of expenditures is devoted to productive investment and away from public consumption.

The volatility of political and economic variables can be shown to be non-monotonic in political power $\xi$.

Proposition 4.3 There exists a unique value $\xi^{*}$ such that $\forall \xi<\xi^{*}$ we have $\frac{\partial \operatorname{Var}\left(\hat{K}_{g}\right)}{\partial \xi}>0$ and $\forall \xi>\xi^{*}$ we have $\frac{\partial \operatorname{Var}\left(\hat{K}_{g}\right)}{\partial \xi}<0$.

Proof See Appendix 8.7.

The reason is that there are two opposing forces driving these volatilities. One is given by the gap between each party's propensities to save, which increases the volatility of policy and allocations. The other force is political stability, which reduces it. When $\xi=0$, both parties are completely symmetric. Even though political turnover reaches its maximum value (with $p_{A}=p_{B}=0.5$ ), the gap is zero (since $s_{A}=s_{B}$ ). So there are no fluctuations in policy or economic variables, and $\sigma^{2}(\xi)=0$, implying $\operatorname{Var}\left(\hat{K}_{g}\right)=0$. As $\xi$ increases, the marginal propensity to invest of type $A$ falls below the symmetric level, while that of type $B$ lies above that value. Hence, the gap in the marginal propensities to invest is widened and volatility rises. For small deviations from symmetry, this effect dominates that of political stability. Eventually, $\xi$ becomes large enough that even though the gap between $s_{A}$ and $s_{B}$ is large, political turnover is very infrequent. Since $B$ is in power most of the time, policy remains stable and volatility goes down. At an extreme, when $\xi=0.5$ party $B$ wins elections with probability one. So there is no variability in policy or allocations.

We can see this graphically in Figure 4 for the set of parameters described in Appendix 8.10.1. As shown in Lemma 4.3, output is more volatile than labor but exhibits less volatility than public and private consumption. The variance of public investment is much larger than that of all other variables because the estimated elasticity of public capital is quite small in this example $(\theta=0.039)$. Therefore, it has been omitted to make the figure more readable.

This result provides a testable implication of the model. Countries in which parties are very symmetric (i.e., there is almost no popularity advantage for any of them) will exhibit frequent turnover but little volatility in policy variables. We should also expect low variability in countries in which turnover is infrequent. Fluctuations are largest for those with intermediate levels of political advantage.

\section{$5 \quad$ Empirical support}

The objective of this section is to test relevant implications of the model. We will first analyze a cross-section of countries for which we have data on political stability at a point 


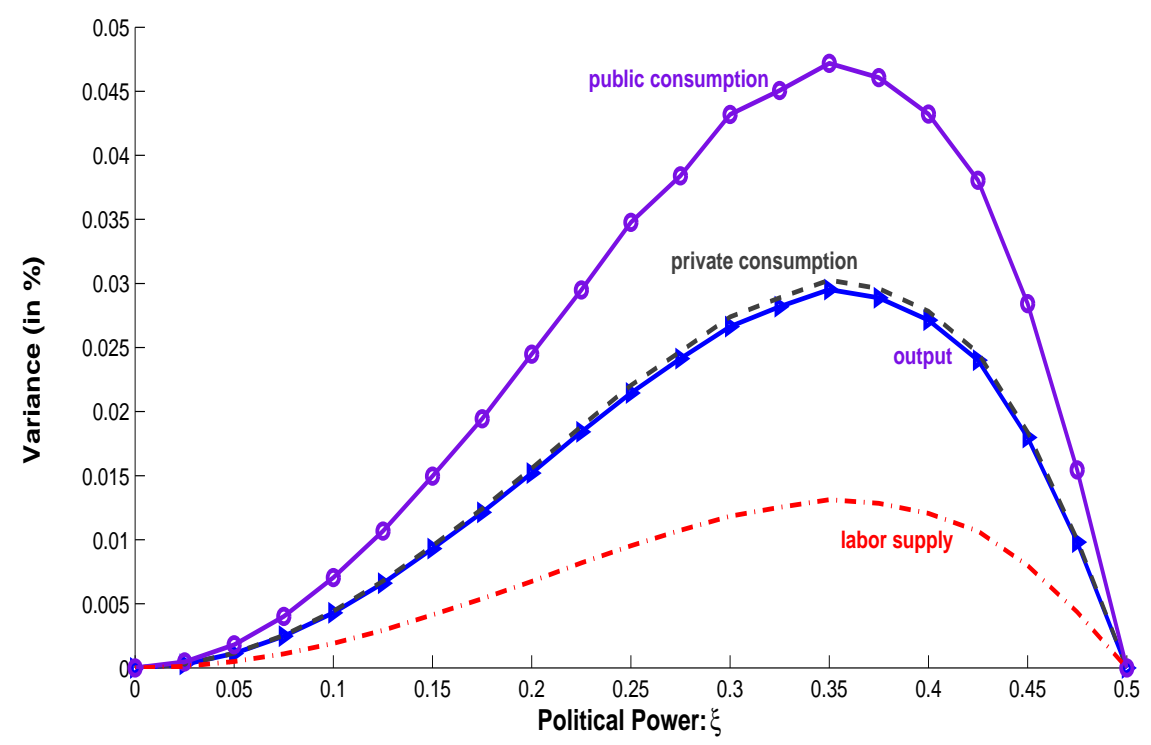

Figure 4: Volatility of policy and allocations, measured by the variance of log-variables

in time. We will then construct a measure of political advantage that is closer to the concept described in the paper for the United States, where we exploit changes in the relative advantage between the two parties over an extensive period of time.

\subsection{Evidence from the cross-section}

The economic data are obtained from Kaminsky, Reinhart, and Végh (2004), who compiled a comprehensive cross-country panel for our main variables of interest from the IMF World Economic Outlook (WEO) and the IMF Government Financial Statistics (GFS) data sets. Output $y$ is gross domestic product. Public consumption $g_{c}$ is consolidated general government consumption and expenditures $e$ are total consolidated government expenditures. The series are deflated using the GDP deflator. Sample lengths for each country are reported in Table 8.10.2, in Appendix 8.10.2. Political stability is obtained from values assigned by the Political Risk Services Group's (PRS) International Country Risk Guide. Following Azzimonti (2010) I use the 1980-1990s average for the variable government stability. ${ }^{9}$ As suggested by the model, more stable economies exhibit larger governments. This can be seen in Figure 5, which shows that political stability and government expenditures are positively related (the correlation between them is 0.54 ). The correlation between political stability and government consumption, on the other hand, is mildly negative, -0.08 , also in line with the model's prediction.

\footnotetext{
${ }^{9}$ Countries are assigned government stability points based on an assessment of the government's ability to carry out its declared programs and its ability to stay in office using PRS' proprietary methodology.
} 


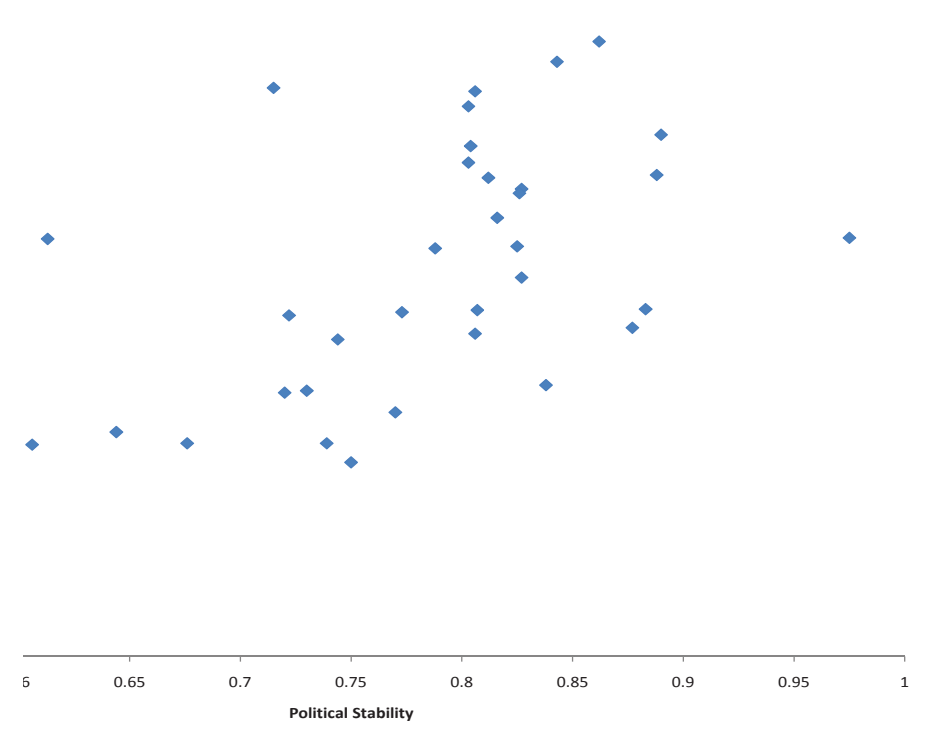

Figure 5: Government expenditures as a percentage of GDP and political stability

\subsection{Evidence from the US}

One implication of the model is that a country should grow faster when the more popular party is in power. Alesina and Roubini (1997) provide some evidence of this by computing an average growth rate of output of $4.24 \%$ under a Democratic government and of $2.41 \%$ under a Republican one in the US (for the sample period 1949-1994). In a standard regression, they found that a change of regime to a Republican (Democratic) administration leads to a fall (increase) in output growth (even after controlling for differences in the exchange rate system, shocks from the rest of the world, etc.). The effects of a change in regime also hold for a sample of industrial (and bipartisan) countries.

Another prediction is that as political advantage $\xi$ goes up, the share of total expenditures devoted to investment increases (while that of public consumption decreases). The bars in Figure 6 represent the variable $A d v_{t}$, measuring the average advantage obtained by the Democrats during all congressional elections to the House of Representatives between 1929 and 2006. The variable is computed as follows. Let $s h_{t}(i)=\frac{i_{t}}{D_{t}+R_{t}}$ denote the share of seats obtained by party $i \in\{R, D\}$ in the House of Representatives in Congress $t \in\left\{70^{n t}, \ldots, 109^{t h}\right\}$ (that is, covering the period 1929-2006). Following Diermeier, Keane and Merlo (2005) the advantage of party $D$ at each period of time is simply $A d v_{t}=s h_{t}(D)-s h_{t}(R)$. Changes in $A d v_{t}$ proxy for movements in $\xi$, the political advantage obtained by the Democratic party over the Republican party during this period.

We can see that Democrats experienced an average advantage since the series is positive for most of the sample. Because this advantage has not been constant over time, it is 


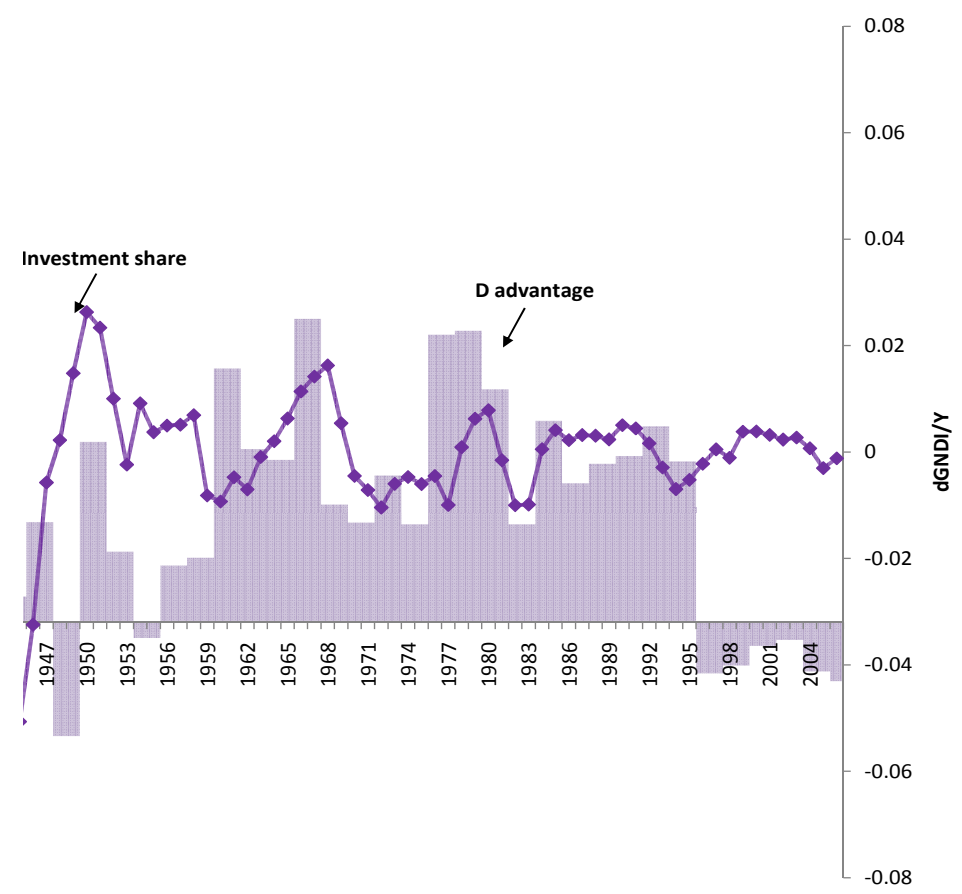

Figure 6: Popularity advantage and investment share, 1929-2006

possible to test our prediction by analyzing how changes in popularity affect the share of public investment.

In order to estimate the investment share as close to the model as possible, I computed it as the ratio of public investment to total government spending,

$$
\text { Investment Share }=\frac{G N D I}{G N D I+G N D C}
$$

where GNDI stands for real non-defense public investment and GNDC for real non-defense public consumption. Both series are obtained from the NIPA tables and deflated by their respective deflators. Notice that I am not using government revenues or total expenditures, since the model does not include debt. The investment share is HP-filtered with $\mathrm{w}=100$ (due to its annual frequency), and represented by a line in Figure 6 . We can see that the popularity advantage and the investment share are positively related. A correlation coefficient of 0.25 provides support for the theory. ${ }^{10}$

\footnotetext{
${ }^{10}$ I must note that the value of $A d v_{t}$ represents the average number of seats at the end of the $t^{\text {th }}$ Congress. If I were to correlate the investment share with the popularity advantage at mid-Congress, the correlation would decrease to 0.18 .
} 


\section{Endogenous political turnover}

The previous sections described how the incentives faced by opposing parties facing reelection uncertainty affected their policy choices. We found that endogenous short-sightedness arises and parties overspend on public goods and underinvest in productive capital in equilibrium. Due to an asymmetry in political power, political cycles propagate into the real economy generating economic cycles. While the channel from politics to economics is well understood from that analysis, the model is silent on the other direction of causality. Can economic factors affect political turnover? Moreover, wouldn't rational politicians choose policy so as to tilt probabilities in their favor?

In this section, I propose an environment in which this issue can be addressed. In particular, I endogenize the re-election probabilities by adding a voting stage into the model following the probabilistic voting literature.

The two groups will alternate in power based on a political institution in which "ideology" or other non-economic issues play a role. In particular, I use a "probabilistic-voting" setup (see Lindbeck and Weibull (1993)) in order to provide micro-foundations for political turnover: The probability of being in power next period is going to be endogenously determined via an electoral process.

A key departure from the traditional probabilistic voting model is that parties do not have a commitment to platforms. Therefore, announcements made during the political campaign will not be credible unless they are optimal ex-post (that is, once the party takes power).

Agents are assumed to differ not only in their preferences over the composition of expenditures but also in another dimension that is orthogonal to economic policy (religious views, charisma of the politician, etc.). Preferences over this political dimension imply derived preferences over candidates and will take the form of additive iid preference shocks $\omega$. The instantaneous utility of agent $j$ in region $J$ at a particular point in time is

$$
\underbrace{u\left(c_{j}, n_{j}\right)+v\left(g^{J}\right)}_{\text {economic }}+\underbrace{\omega_{j}}_{\text {political }},
$$

\section{Timing}

Each period will be divided into two stages: the taxation stage and the election stage.

At the taxation stage, the incumbent chooses $\tau, g^{A}, g^{B}$, and $K_{g}^{\prime}$ knowing the state of the economy $\left(K_{g}\right)$ and the distribution of political shocks but not their realized values. Hence, policy is chosen under uncertainty. The probability of winning the election can be calculated by forecasting how agents vote given different realizations of the shock.

After production, consumption, and investment take place, $\omega^{\prime}$ is realized. At the election stage, agents vote for the party that gives them higher expected lifetime utility. They need to forecast how the winner of the election chooses policy. The assumptions of rationality and perfect foresight imply that agents' predictions are correct in equilibrium. 
The set of equilibrium functions to be determined in a Markov-perfect equilibrium is identical to the one in previous sections, with the addition of two new functions: The probabilities of re-election $p_{i}\left(K_{g}\right)$, which are now endogenous objects.

\section{Election Stage}

At this stage, agents must decide which party to vote for. The utility derived from political factors, $\omega_{j}$, has two components: An individual ideology bias (denoted by $\varphi^{j J}$ ) and an overall popularity bias $(\psi)$. In particular,

$$
\omega_{i}=\left(\psi+\varphi^{j J}\right) I_{i}
$$

where $I$ is an indicator function such that $I_{B}=1$ and $I_{A}=0$, since $\psi$ and the individual specific parameter $\varphi^{j J}$ measure voter $j$ 's ideological bias toward the candidate from party $B$. I will follow Persson and Tabellini (2000) by assuming that the distribution of $\varphi^{j J}$ is uniform and group-specific, $\varphi^{j J} \backsim\left[-\frac{1}{2 \phi^{J}}, \frac{1}{2 \phi^{J}}\right]$, with $J=A, B$.

These shocks are iid over time and hence are 'candidate specific.' Each period, a given party presents a candidate and voters form expectations about the candidate's position on certain moral, ethnic or religious issues, orthogonal to the provision of public goods. Examples are attitudes toward crime (gun control or capital punishment), drugs (e.g., whether to legalize the use of marijuana), immigration policies, pro-life or pro-choice positions, samesex marriage, etc. Since $\varphi^{j J}$ can take positive or negative values, there are members in each group who are biased toward both candidates. Therefore, individuals belonging to the same group may vote differently.

The parameter $\psi$ represents a general bias toward party $B$ at each point in time. It measures the average relative popularity of candidates from that party relative to those from party $A$. While the realization of $\varphi^{j J}$ is individual-specific, the value of $\psi$ is the same for all agents. ${ }^{11}$ This is the most essential shock, since by being common to all agents, it is the one that affects the election outcome. The role of $\varphi^{j J}$ is to ensure the existence of equilibria by ruling out ties and is included mostly for technical reasons. The popularity shock is iid over time and can also take positive or negative values. It is distributed according to:

$$
\psi \backsim\left[-\frac{1}{2}+\eta, \frac{1}{2}+\eta\right]
$$

A positive value for $\eta$ (the expected value of $\psi$ ) implies that candidates from party $B$ have an average popularity advantage over those from the opposition. On the other hand, $\eta=0$ implies that parties are symmetric, in the sense that their candidates are expected to be equally popular or charismatic. This parameter will be the main driving force behind the electoral advantage.

\footnotetext{
${ }^{11}$ Political scientists refer to this parameter as valence, referring to "issues on which parties or leaders are differentiated not by what they advocate but by the degree to which they are linked in the public's mind with conditions or goals or symbols of which almost everyone approves or disapproves" (Stokes, 1992).
} 
Finally, agents are assumed to have perfect information about the candidates, so there are no informational asymmetries in this model. At the election stage, voters compare their lifetime utility under the alternative parties. The maximization problem of voter $j$ in group $A$ is given by

$$
\max \left\{V_{A}\left(K_{g}^{\prime}\right), W_{A}\left(K_{g}^{\prime}\right)+\psi^{\prime}+\varphi^{j A^{\prime}}\right\},
$$

where $V_{A}\left(K_{g}^{\prime}\right)$ denotes the welfare of this agent if a candidate representing his group wins the elections, while $W_{A}\left(K_{g}^{\prime}\right)$ is the value of his utility if the candidate representing group $B$ is elected. The maximization problem of an agent in group $B$ is analogously defined.

\section{Determination of probabilities}

Individual $j \in A$ votes for $B$ whenever the shocks are such that

$$
V_{A}\left(K_{g}^{\prime}\right)<W_{A}\left(K_{g}^{\prime}\right)+\psi^{\prime}+\varphi^{j A \prime} .
$$

We can identify the swing voter in group $A$ as the voter whose value of $\varphi^{j A \prime}$ makes him indifferent between the two parties

$$
\varphi^{A}\left(K_{g}^{\prime}\right)=V_{A}\left(K_{g}^{\prime}\right)-W_{A}\left(K_{g}^{\prime}\right)-\psi^{\prime} .
$$

Figure 7 illustrates this point (assuming $\psi=0$ for simplicity). The swing voter is found where the two solid lines intersect. All voters in group $A$ with $\varphi^{j A^{\prime}}>\varphi^{A}\left(K_{g}^{\prime}\right)$ also prefer party $B$ as can be seen in the graph.

The same type of analysis can be performed for agents in group $B$, to determine the swing voter in that group.

Given the assumptions about the distributions of $\varphi^{j A}$ and $\varphi^{j B}$ the share of votes for party $B$ is:

$$
\pi_{B}=\frac{1}{2}\left[1-\sum_{J} \phi^{J} \varphi^{J}\left(K_{g}^{\prime}\right)\right] .
$$

Under majority voting, party $B$ wins if it can obtain more than half of the electorate; that is, if $\pi_{B}>\frac{1}{2}$. This occurs whenever its relative popularity is high enough. There exists a threshold for $\psi$, denoted by $\psi^{*}\left(K_{g}^{\prime}\right)$ such that $B$ wins for any realization $\psi>\psi^{*}\left(K_{g}^{\prime}\right)$. After performing some algebra using the expression above, we find that

$$
\psi^{*}\left(K_{g}^{\prime}\right)=\frac{1}{\phi}\left(\phi^{A}\left[V_{A}\left(K_{g}^{\prime}\right)-W_{A}\left(K_{g}^{\prime}\right)\right]+\phi^{B}\left[W_{B}\left(K_{g}^{\prime}\right)-V_{B}\left(K_{g}^{\prime}\right)\right]\right),
$$

where $\phi=\phi^{A}+\phi^{B}$.

The threshold is given by a weighted sum of the differences in the utility of the swing voter under each party. The weights depend on the dispersion in the ideology shocks and on the amount of supporters that each party has. The higher the heterogeneity within a constituency $\left(\phi^{J}\right)$, the bigger the effect these factors have on the election outcomes. Also, 


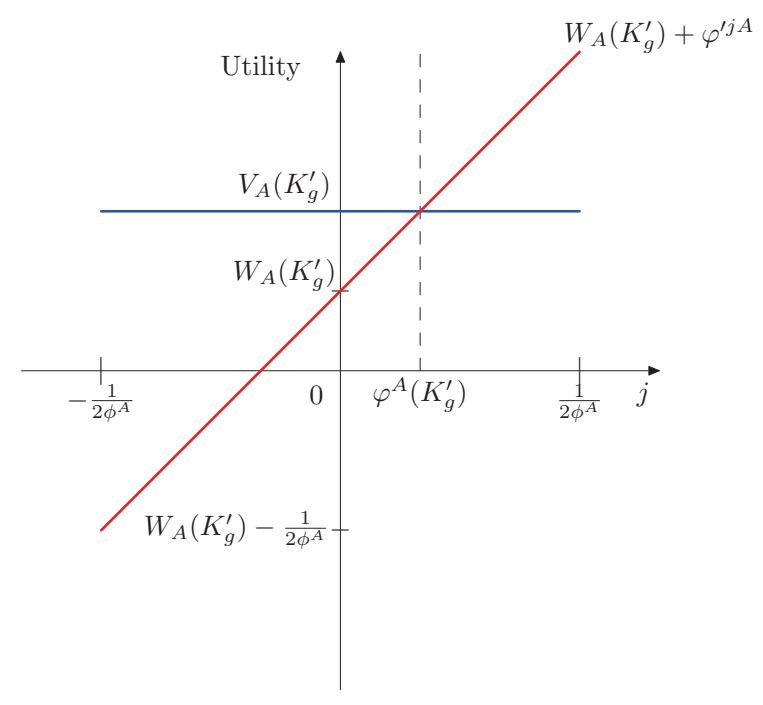

Figure 7: Utility as a function of $\varphi^{j A \prime}$

the greater the number of individuals belonging to type $J$, the stronger the group in the determination of the probability. Finally, note that the threshold depends on the level of public capital, though it is not clear in which direction. In principle, this level could increase or decrease with $K_{g}^{\prime}$.

Since $\varphi^{J}\left(K_{g}^{\prime}\right)$ depends on the realized value of $\psi$, ex-ante the share of votes for party $B$ $\left(\pi_{B}\right)$ is a random variable. $B$ 's probability of winning the election is given by:

$$
p_{B}\left(K_{g}^{\prime}\right)=P\left(\pi_{B}>\frac{1}{2}\right)=P\left(\psi^{\prime}>\psi^{*}\left(K_{g}^{\prime}\right)\right)
$$

which is equivalent to:

$$
p_{B}\left(K_{g}^{\prime}\right)=\frac{1}{2}+\left[\eta-\psi^{*}\left(K_{g}^{\prime}\right)\right] .
$$

$A^{\prime}$ 's probability of winning the next election is just $p_{A}\left(K_{g}^{\prime}\right)=1-p_{B}\left(K_{g}^{\prime}\right)$.

Recall that $\eta$ represents the popularity advantage of candidates from party $B$ over those from party $A$. So in principle, $B$ 's probability increases with $\eta$.

The current level of consumption in private and public capital does not affect the voting decision (i.e., no retrospective voting). Voters do not 'punish' politicians/parties for their past behavior but decide instead based on future expected policy choices.

\section{Taxation Stage}


The maximization problem looks exactly like the one presented in section 3 , with the exception that probabilities now depend on the state variable and utility depends on ideological preference shocks. To fix ideas, consider the problem faced by an incumbent from group $B$

$$
\max _{g^{A}, g^{B}, K_{g}^{\prime} \geq 0} u(c, n)+v\left(g^{B}\right)+\omega_{j}+\beta\left\{p_{B}\left(K_{g}^{\prime}\right) V_{B}\left(K_{g}^{\prime}\right)+p_{A}\left(K_{g}^{\prime}\right) W_{B}\left(K_{g}^{\prime}\right)+E_{B}\left(\omega_{j}^{\prime} ; K_{g}^{\prime}\right)\right\}
$$

where consumption and labor satisfy equations $(2)$ and $(3) . E_{B}\left(\omega_{j}^{\prime}, K_{g}^{\prime}\right)$ represents the expected value of tomorrow's political shock conditional on $B$ winning the next election (recall that this shock is a relative bias toward a candidate from party $B$ ),

$$
E_{B}\left(\omega_{j}^{\prime} ; K_{g}^{\prime}\right)=\int_{\psi^{*}\left(K_{g}^{\prime}\right)}^{\frac{1}{2}+\eta} z \partial z,
$$

which can be shown to be equal to

$$
E_{B}\left(\omega_{j}^{\prime} ; K_{g}^{\prime}\right)=p_{B}\left(K_{g}^{\prime}\right)\left[\frac{1}{2} p_{A}\left(K_{g}^{\prime}\right)+\eta\right] .
$$

By changing the stock of public capital the incumbent affects not only the economic dimension but also his probability of winning and the expected value of political shocks. ${ }^{12}$

The functions $V_{B}\left(K_{g}\right)$ and $W_{B}\left(K_{g}\right)$ satisfy

$$
\begin{gathered}
V_{B}\left(K_{g}\right)=u\left(c_{B}\left(K_{g}\right), n_{B}\left(K_{g}\right)\right)+v\left(g_{B}^{B}\left(K_{g}\right)\right)+ \\
\beta\left\{p_{B}\left(h_{B}\left(K_{g}\right)\right) V_{B}\left(h_{B}\left(K_{g}\right)\right)+p_{A}\left(h_{B}\left(K_{g}\right)\right) W_{B}\left(h_{B}\left(K_{g}\right)\right)+E_{B}\left(\omega_{j}^{\prime} ; h_{B}\left(K_{g}\right)\right)\right\}
\end{gathered}
$$

and

$$
\begin{gathered}
W_{B}\left(K_{g}\right)=u\left(c_{A}\left(K_{g}\right), n_{A}\left(K_{g}\right)\right)+v\left(g_{A}^{B}\left(K_{g}\right)\right) \\
\beta\left\{p_{B}\left(h_{A}\left(K_{g}\right)\right) V_{B}\left(h_{A}\left(K_{g}\right)\right)+p_{A}\left(h_{A}\left(K_{g}\right)\right) W_{B}\left(h_{A}\left(K_{g}\right)\right)+E_{B}\left(\omega_{j}^{\prime} ; h_{A}\left(K_{g}\right)\right)\right\},
\end{gathered}
$$

where $\Upsilon_{i}\left(K_{g}\right)=\left\{g_{i}^{A}\left(K_{g}\right), g_{i}^{B}\left(K_{g}\right), h_{i}\left(K_{g}\right)\right\}$ denotes the equilibrium policy functions chosen by incumbent type $i$, and where $c_{i}\left(K_{g}\right)=c\left(\Upsilon_{i}\left(K_{g}\right)\right)$ and $n_{i}\left(K_{g}\right)=n\left(\Upsilon_{i}\left(K_{g}\right)\right)$ are the competitive equilibrium values of consumption and labor under the political equilibrium policies.

Because the choice of expenditures is static, it is identical to the one under exogenous political turnover.

The investment decision, on the other hand, now depends on how public investment affects the probability of re-election

$$
u_{1}\left(c_{B}\left(K_{g}\right), n_{B}\left(K_{g}\right)\right)=\beta\left\{p_{B}\left(K_{g}^{\prime}\right) V_{B 1}\left(K_{g}^{\prime}\right)+p_{A}\left(K_{g}^{\prime}\right) W_{B 1}\left(K_{g}^{\prime}\right)\right.
$$

\footnotetext{
${ }^{12}$ Other papers in the literature usually ignore political shocks because they study two-period models, once the shock has been realized. Since $\omega$ is additive, focusing on net-of-shock welfare is without loss of generality. In this paper, it would not be the case because that elections are held every period.
} 


$$
\left.+p_{B 1}\left(K_{g}^{\prime}\right)\left[V_{B}\left(K_{g}^{\prime}\right)-W_{B}\left(K_{g}^{\prime}\right)\right]+E_{B 2}\left(\omega_{j}^{\prime} ; K_{g}^{\prime}\right)\right\},
$$

where $p_{B 1}\left(K_{g}^{\prime}\right)=\frac{\partial p_{B}\left(K_{g}^{\prime}\right)}{\partial K_{g}^{\prime}}$, and we use the fact that $p_{A}=1-p_{B}$.

Even though parties represent their constituencies and have no derived value of being in office, they will try to manipulate the probability of being re-elected (which allows them to implement the desired policy in the future).

A change in investment today modifies the problem faced by voters, which in turn affects the probability of being in power next period. A rational incumbent realizes this and thus takes into account the effect of expanding $K_{g}^{\prime}$ on its likelihood of winning. It is reasonable to expect that a group is better off while in power, so $V_{B}\left(K_{g}^{\prime}\right)>W_{B}\left(K_{g}^{\prime}\right)$. However, the sign of $p_{B 1}\left(K_{g}^{\prime}\right)$ is, in principle, ambiguous.

Under our functional assumptions, we can show that $p_{B 1}\left(K_{g}^{\prime}\right)=0$ in a differentiable MPE. Intuitively, if candidate $B$ proposes a higher level of investment, it will create a wedge in the marginal utilites derived from the two candidates. This margin, however, is independent of the stock of public capital in the economy. The reason is that (the natural logarithm of) capital appears additively separably from other arguments in all welfare functions $V_{i}$ and $W_{i}$. Inspection of equation 17 reveals that the threshold value $\psi^{*}$ is independent of $K_{g}$, and so is the re-election probability (see eq. 18). As a result, the probabilities of re-election are constant $p_{i}\left(K_{g}\right)=p_{i}$ for $i=A, B$. Marginal utilities, on the other hand, are affected by the marginal propensities to invest. Therefore, the probabilities of re-election are functions of these, as shown in Proposition 6.1.

\section{Proposition 6.1}

$$
g_{i}\left(K_{g}\right)=\frac{1}{2}\left(1-s_{i}\right) \tilde{A} K_{g}^{\bar{\theta}}-G \quad \text { and } \quad h_{i}\left(K_{g}\right)=s_{i} \tilde{A} K_{g}^{\bar{\theta}},
$$

The marginal propensities to invest $s_{i}$ and the probabilities of re-election $p_{i}$ are jointly determined by:

$$
s_{i}=\bar{\theta} \beta\left[\frac{1+p_{i}}{2-\bar{\theta} \beta\left(1-p_{i}\right)}\right] .
$$

The probabilities of reelection are $p_{B}=\frac{1}{2}+\left[\eta-\psi^{*}\right]$ and $p_{A}=1-p_{B}$, where

$$
\psi^{*}=\frac{3}{2}\left[\ln \left(\frac{1-s_{A}}{1-s_{B}}\right)+\frac{\bar{\theta} \beta}{1-\bar{\theta} \beta} \ln \frac{s_{A}}{s_{B}}\right] .
$$

Proof See Appendix 8.8.

Because $p_{i}$ is independent of the stock of capital, the policy rules chosen by the government $g_{i}\left(K_{g}\right)$ and $h_{i}\left(K_{g}\right)$ take exactly the same form as in Proposition 6.1. The main difference is that there is now some feedback from policy decisions to political turnover since the probabilities of winning an election are in turn functions of the propensities to invest. If $s_{B}>s_{A}$, forward-looking voters realize that candidates from party $B$ spend relatively more resources in productive activities than the opposition. This increases $B^{\prime} s$ chances of 
re-election. On the other hand, higher investment in public capital implies more taxes and lower consumption than under party $A$. This force pushes down the likelihood of $B$ being re-elected. Overall it is not clear whether $p_{A} \lessgtr p_{B}$ when $s_{B}>s_{A}$.

In equilibrium, probabilities of re-elections are jointly determined with propensities to invest. We have a system of four non-linear equations in four unknowns $\left(p_{A}, p_{B}, s_{A}\right.$ and $\left.s_{B}\right)$. From Proposition 6.1 it is clear that if $\eta=0$, then the equilibrium is symmetric with $s_{A}=s_{B}$ and $p_{A}=p_{B}=\frac{1}{2}$. Proposition 6.2 establishes that when $\eta>0$, the equilibrium will be asymmetric.

Proposition 6.2 Let $\eta>0$. Then party $B$ has a popularity advantage, and as a result, it invest more and it will be re-elected more often than the opposition

$$
s_{A}<s_{B}<s^{*} \quad \text { and } \quad p_{A}<\frac{1}{2}<p_{B} .
$$

Proof See Appendix 8.9

When $\eta>0$, party $B$ has an advantage over $A$ because positive realizations of the popularity shock are more likely. This tilts the utility of all voters in $B^{\prime}$ s favor, which in turn increases the probability of winning the next election. From the optimality condition (eq. (11)), this creates incentives to invest more. The opposite occurs with party $A$. Given his low chances of being in power next period, the incumbent is inclined toward unproductive expenditures. In this example, we see a virtuous circle: If individuals believe that one party has on average 'better' candidates (on aspects orthogonal to the management of economic policy), the strategic effects imply that they will indeed behave 'better' in choosing policy (overspend less on the unproductive region-specific goods). Despite the fact that $B$ 's investment decision is closer than $A$ 's decision to the one that would be undertaken by a planner, $B$ 's saving propensity is lower than the first best, $s^{*}$. This is a result of the short-sightedness created by the political uncertainty and the disagreement over the composition of expenditures.

This result implies that some caution should be taken when inferring unobservable characteristics from observable actions in at least two respects. First, the source of asymmetry is completely unrelated to how 'competent' candidates from different parties are. Suppose that we observe an economy in which the average level of output and investment on infrastructure is higher under one of the parties, while spending on unproductive activities is lower. It would be incorrect to infer that candidates belonging to such a party are more 'capable' or 'efficient' in dealing with economic issues. This observed outcome could be the result of equilibrium actions consistent with our model, in which even though parties have identical investment technologies, political considerations make them choose different strategies. Second, preferences over productive and unproductive spending are completely symmetric here. In the absence of political advantages, both parties would invest equal proportions of available resources while spending the same amount on public goods. The difference in policy choices in the asymmetric case is a result of strategic considerations 
and does not rely on preference spending biases (i.e., differences in the weights each group assigns to the provision of public goods).

Finally, note that only in the symmetric case $\eta=0$ does the threshold level $\psi^{*}=0$. As long as party $B$ enjoys an ideological advantage, $\psi^{*} \neq 0$. Hence, the probability of reelection cannot be taken as an exogenous object in empirical estimations government policy's response to political turnover. Re-election probabilities and spending (and investment) rates are jointly determined and, taking $p_{i}$ as given, would deliver biased estimates. Measures of ideological advantage could help us quantify, with the help of the model, the size of such biases.

\section{Concluding Remarks}

I presented a model in which disagreements about the composition of spending results in implementation of myopic policies by the government: Investment in infrastructure is too low while spending on public goods is too high. Groups with conflicting interests try to gain power in order to implement their preferred fiscal plan. Since there is a chance of being replaced by the opposition, strategic manipulation of the level of investment is optimal.

I considered a case in which ideological biases toward candidates from one of the groups give them an advantage in the political arena. As a result, the voting equilibrium is asymmetric and public investment is not only inefficiently low but it also fluctuates. The group with the advantage wins elections more often, becoming less impatient. Therefore, it chooses a share of investment to GDP closer to the first best. Even though both groups have symmetric preferences over the size of spending and investment, in equilibrium the group with the disadvantage tends to spend more and invest less. Since different policies are implemented as parties alternate in power, the political cycle is propagated throughout the real economy. In equilibrium, macroeconomic variables fluctuate even in the absence of economic shocks. Moreover, consumption, employment and output are distorted despite the fact that the government has access to lump-sum taxation. Increases in the political advantage induce increases in the share of public investment to total expenditures by the advantaged party. I show that this is roughly consistent with evidence from the US for the period 19292006. Volatility is non-monotonic in the degree of electoral advantage. Economies with intermediate values of this variable are expected to exhibit the largest volatility in political and economic variables. 


\section{Appendix}

\subsection{Proof of Proposition 3.1}

The FOC with respect to $K_{g}^{\prime}$ is:

$$
u_{1}\left(c_{B}\left(K_{g}\right), n_{B}\left(K_{g}\right)\right)=\beta\left\{p_{B} V_{B 1}\left(K_{g}^{\prime}\right)+p_{A} W_{B 1}\left(K_{g}^{\prime}\right)\right.
$$

Denote the rule that solves this functional equation by $h_{B}\left(K_{g}\right) \equiv K_{B}$. Define $h_{A}\left(K_{g}\right) \equiv$ $K_{A}$ analogously.

Focus on the problem of party $B$ (and abstract from the subindexes in its value function). Obtain $V_{1}\left(K_{g}\right)$ by differentiating equation 8 and simplifying:

$$
V_{1}\left(K_{g}\right)=u_{1}\left(c_{B}\left(K_{g}\right), n_{B}\left(K_{g}\right)\right) F_{1}\left(K_{g}, n_{B}\left(K_{g}\right)\right) .
$$

To find $W_{1}\left(K_{g}\right)$ differentiate equation $(9)$ :

$$
W_{1}\left(K_{g}\right)=u_{1}\left(c_{A}\left(K_{g}\right), n_{A}\left(K_{g}\right)\right) c_{A 1}\left(K_{g}\right)+\beta h_{A 1}\left(K_{g}\right)\left\{p_{B} V_{1}\left(K_{A}\right)+p_{A} W_{1}\left(K_{A}\right)\right\},
$$

where $c_{A 1}\left(K_{g}\right)=F_{1}\left(K_{g}, n_{A}\left(K_{g}\right)\right)-x_{g}\left(g_{A}\left(K_{g}\right)\right) g_{A 1}\left(K_{g}\right)-h_{A 1}\left(K_{g}\right)$. Notice that allocations are evaluated given party $A$ 's policy, because we are considering the value function of a type $B$ agent when his group is out of power.

Use eq. (23) to solve for $W_{1}\left(h_{B}\left(K_{g}\right)\right)$ :

$$
W_{1}\left(K_{B}\right)=\frac{1}{p_{A}}\left\{\frac{1}{\beta} u_{1}\left(c_{B}\left(K_{g}\right), n_{B}\left(K_{g}\right)\right)-p_{B} V_{1}\left(K_{B}\right)\right.
$$

In order to replace the equation above in eq. (25) we need the value function to be evaluated in the investment choice of government $A, W_{1}\left(K_{A}\right)$. Assuming that the functions $h_{i}$ are invertible, we can achieve this by evaluating eq. (26) at $\tilde{K}_{g}=h_{B}^{-1}\left(h_{A}\left(K_{g}\right)\right)$,

$$
W_{1}\left(K_{A}\right)=\frac{1}{p_{A}}\left\{\frac{1}{\beta} u_{c}\left(c_{B}\left(\tilde{K}_{g}\right), n_{B}\left(\tilde{K}_{g}\right)\right)-p_{B} V_{1}\left(K_{A}\right)\right.
$$

Replace eq. (27) into eq. (25) and simplify:

$$
\begin{gathered}
W_{1}\left(K_{g}\right)=u_{1}\left(c_{A}\left(K_{g}\right), n_{A}\left(K_{g}\right)\right)\left[F_{1}\left(K_{g}, n_{A}\left(K_{g}\right)\right)-x_{g}\left(g_{A}\left(K_{g}\right)\right) g_{A 1}\left(K_{g}\right)\right] \\
\left.-h_{A 1}\left(K_{g}\right)\left[u_{1}\left(c_{A}\left(K_{g}\right), n_{A}\left(K_{g}\right)\right)-u_{c}\left(c_{B}\left(\tilde{K}_{g}\right)\right), n_{B}\left(\tilde{K}_{g}\right)\right)\right] .
\end{gathered}
$$

Update eq.(28) by substituting $K_{g}$ with $K_{g}^{\prime}=h_{B}\left(K_{g}\right)$ and replace in eq.(23). After some manipulations, we obtain

$$
\begin{gathered}
u_{1}\left(c_{B}\left(K_{g}\right), n_{B}\left(K_{g}\right)\right)=\beta\left\{\sum_{i=A, B} p_{i} u_{1}\left(c_{i}\left(K_{g}^{\prime}\right), n_{i}\left(K_{g}^{\prime}\right)\right) F_{1}\left(K_{g}^{\prime}, n_{i}\left(K_{g}^{\prime}\right)\right)\right. \\
-p_{A} x_{g}\left(g_{A}\left(K_{g}^{\prime}\right)\right) g_{A 1}\left(K_{g}^{\prime}\right) u_{1}\left(c_{A}\left(K_{g}^{\prime}\right), n_{A}\left(K_{g}^{\prime}\right)\right) \\
\left.\left.-h_{A 1}\left(K_{g}^{\prime}\right) p_{A}\left[u_{1}\left(c_{A}\left(K_{g}^{\prime}\right), n_{A}\left(K_{g}^{\prime}\right)\right)-u_{c}\left(c_{B}\left(\tilde{K}_{g}^{\prime}\right)\right), n_{B}\left(\tilde{K}_{g}^{\prime}\right)\right)\right]\right\} .
\end{gathered}
$$




\subsection{Proof of Proposition 4.1}

Guess a constant investment share $h_{i}\left(K_{g}\right)=s_{i} \tilde{A} K_{g}^{\bar{\theta}}$. Eq. (10) implies:

$$
g_{B}\left(K_{g}\right)=\hat{c}_{B}\left(K_{g}\right)=\frac{1}{2}\left(1-s_{B}\right) \tilde{A} K_{g}^{\bar{\theta}}
$$

with $\hat{c}_{B}\left(K_{g}\right)=c_{B}\left(K_{g}\right)-\frac{n_{B}\left(K_{g}\right)^{1+\epsilon}}{1+\epsilon}$. Equation (11) simplifies to:

$$
\begin{gathered}
\frac{1}{\hat{c}_{B}\left(K_{g}\right)}=\beta\left\{p_{B} \frac{f_{K}\left(K_{g}^{\prime}\right)}{\hat{c}_{B}\left(K_{g}^{\prime}\right)}+\left(1-p_{B}\right) \frac{\left[f_{K}\left(K_{g}^{\prime}\right)-g_{B K}\left(K_{g}\right)\right]}{\hat{c}_{A}\left(K_{g}^{\prime}\right)}+\right. \\
\left.\left(1-p_{B}\right) h_{A K}\left(K_{g}^{\prime}\right)\left[-\frac{1}{\hat{c}_{A}\left(K_{g}^{\prime}\right)}+\frac{1}{\tilde{c}_{B}\left(K_{g}^{\prime}\right)}\right]\right\} .
\end{gathered}
$$

where $K_{g}^{\prime}=h_{B}\left(K_{g}\right)=s_{B} \tilde{A} K_{g}^{\bar{\theta}}$ and $\tilde{c}_{B}\left(K_{g}^{\prime}\right)=\frac{1}{2} \frac{1-s_{B}}{s_{B}} s_{A} \tilde{A} K_{g}^{\prime \bar{\theta}}$.

Replacing the guess into the equation above and simplifying,

$$
s_{B}=\frac{\beta \bar{\theta}\left(1+p_{B}\right)}{2-\beta \bar{\theta}\left(1-p_{B}\right)} .
$$

\subsection{Proof of Proposition 4.2}

Let $N=\left[K_{g A}^{s s}, K_{g B}^{s s}\right]$ define the ergodic set. We will prove the proposition in two steps: first, by showing that any sequence starting outside of the set necessarily converges to a point inside the set; second, by showing that any sequence starting inside $N$ necessarily stays in $N$.

Step 1. Let $0<K_{g 0}<K_{g A}^{s s}$. Define the sets $M_{i}=\left[0, K_{g i}^{s s}\right]$ and $Q_{i}=\left[K_{g i}^{s s}, \infty\right) \Rightarrow$ $\forall K_{g} \in \operatorname{int}\left(M_{i}\right), h_{i}^{\prime}\left(K_{g}\right)>1$ and $\forall K_{g} \in \operatorname{int}\left(Q_{i}\right), h_{i}^{\prime}\left(K_{g}\right)<1$. Let $K_{g} \in M_{A} \cap M_{B} \equiv M$, then we know that $K_{g}^{\prime}>h_{i}\left(K_{g}\right)$ from Lemma 4.1 for $i \in\{A, B\}$. Hence, if $K_{g 0} \in M$ the sequence $\left\{K_{g t}\right\}_{t}$ is increasing. Moreover, $\exists T<\infty$ such that $K_{g T}>K_{g A}^{s s}$. Suppose not. Since $M$ is bounded and $\left\{K_{g t}\right\}_{t}$ is increasing, then the series must converge to the upper bound $K_{g A}^{s s}$. But $h_{B}\left(K_{g A}^{s s}\right)>K_{g A}^{s s}$ from Lemma 4.1 and the fact that $s_{B}>s_{A}$. Contradiction.

Now let $K_{g} \in Q_{A} \cap Q_{B} \equiv Q$, then we know that $K_{g}^{\prime}<h_{i}\left(K_{g}\right)$ from Lemma 4.1 for $i \in\{A, B\}$. Hence, if $K_{g 0} \in Q$ the sequence $\left\{K_{g t}\right\}_{t}$ is decreasing. Moreover, $\exists T^{\prime}<\infty$ such that $K_{g T^{\prime}}<K_{g B}^{s s}$. Suppose not. Since $Q$ is bounded below and $\left\{K_{g t}\right\}_{t}$ is decreasing, then the series must converge to the lower bound $K_{g B}^{s s}$. But $h_{A}\left(K_{g B}^{s s}\right)>K_{g B}^{s s}$ from Lemma 4.1 and the fact that $s_{B}>s_{A}$. Contradiction.

Step 2. Let $K_{g t} \in N$, then there are two possibilities. Either $i=A$, in which case $K_{g t+1}=h_{A}\left(K_{g t}\right) \geq K_{g A}^{s s}$ from Lemma 4.1, so $K_{g t+1} \in N$. Alternatively, if $i=B$, then $K_{g t+1}=h_{B}\left(K_{g t}\right) \leq K_{g B}^{s s}$ from Lemma 4.1, so $K_{g t+1} \in N$. 


\subsection{Proof of Lemma 4.3}

In parts.

$$
\begin{aligned}
& \operatorname{Var}\left(\hat{y}_{t}\right)<\operatorname{Var}\left(\hat{K}_{g t}\right): \text { Since } \hat{y}_{t}=\log \tilde{A}+\bar{\theta} \hat{K}_{g t} \Rightarrow \operatorname{Var}\left(\hat{y}_{t}\right)=\bar{\theta}^{2} \operatorname{Var}\left(\hat{K}_{g t}\right)<\operatorname{Var}\left(\hat{K}_{g t}\right) . \\
& \operatorname{Var}\left(\hat{n}_{t}\right)<\operatorname{Var}\left(\hat{y}_{t}\right): \text { Take logarithms to equation }(12), \text { then } \operatorname{Var}\left(\hat{n}_{t}\right)=\left(\bar{\theta}-\frac{\theta}{1+\theta \epsilon}\right)^{2} \operatorname{Var}\left(\hat{K}_{g t}\right) . \\
& \operatorname{Var}\left(\hat{c}_{t}\right)=\operatorname{Var}(\log (g+G)): \text { Trivial from } \hat{c}_{t}=\log (0.5 \tilde{A})+\log \left(1-s_{t}\right)+\bar{\theta} \hat{K}_{g t}=\log (g+G) . \\
& \operatorname{Var}\left(\hat{c}_{t}\right)>\operatorname{Var}\left(\hat{y}_{t}\right): \text { The variance of } \hat{c}_{t} \text { is } \\
& \operatorname{Var}\left(\hat{c}_{t}\right)=\operatorname{Var}\left(\log \left(1-s_{t}\right)\right)+\bar{\theta}^{2} \operatorname{Var}\left(\hat{K}_{g t}\right)+2 \bar{\theta} \operatorname{Cov}\left(\log \left(1-s_{t}\right), \log s_{t-1}\right),
\end{aligned}
$$

from the expression for $\hat{c}_{t}$ and the definitions of $\hat{K}_{g t}$ and $\hat{\epsilon}_{t}$. Finally, $\bar{\theta}^{2} \operatorname{Var}\left(\hat{K}_{g t}\right)=$ $\operatorname{Var}\left(\hat{y}_{t}\right)$ and $\operatorname{Cov}\left(\log \left(1-s_{t}\right), \log s_{t-1}\right)=0$ because political shocks are i.i.d..

\subsection{Proof of Lemma 4.4}

Let $\sigma_{x}$ denote the standard deviation of variable $x$. Public investment is proportional to output, $I_{g}=s y$. Taking logs, we can compute

$$
\rho\left(\hat{I}_{g t}, \hat{y}_{t}\right)=\frac{\operatorname{Cov}\left(\hat{s}_{t}+\hat{y}_{t}, \hat{y}_{t}\right)}{\sigma_{\hat{y}} \sigma_{\hat{I}_{g}}}=\frac{\sigma_{\hat{y}}}{\sigma_{\hat{I}_{g}}}>0
$$

since $s_{t}$ and $y_{t}$ are uncorrelated.

Consumption is proportional to output, $c=0.5(1-s) y$. Taking logs,

$$
\rho\left(\hat{c}_{t}, \hat{y}_{t}\right)=\frac{\operatorname{Cov}\left(\log \left(0.5\left[1-s_{t}\right]\right)+\hat{y}_{t}, \hat{y}_{t}\right)}{\sigma_{\hat{y}} \sigma_{\hat{c}}}=\frac{\sigma_{\hat{y}}}{\sigma_{\hat{c}}}>0 .
$$

From the definition of public consumption $\rho\left(\hat{c}_{t}, \hat{y}_{t}\right)=\rho\left(\hat{x}\left(g_{t}\right), \hat{y}_{t}\right)$. The correlation of labor supply with output can be computed in a similar way.

\subsection{Proof of Lemma 4.5}

Differentiating condition $i$. in Lemma 4.2 we obtain

$$
\begin{gathered}
\frac{\partial E\left(\hat{K}_{g}\right)}{\partial \xi}=\frac{1}{1-\bar{\theta}^{2}}\left(p_{B} \frac{\partial s_{B}}{\partial p_{B}} \frac{1}{s_{B}}-p_{A} \frac{\partial s_{A}}{\partial p_{A}} \frac{1}{s_{A}}+\hat{s}_{B}-\hat{s}_{A}\right) \\
>p_{B} \frac{\partial s_{B}}{\partial p_{B}} \frac{1}{s_{B}}-p_{A} \frac{\partial s_{A}}{\partial p_{A}} \frac{1}{s_{A}}
\end{gathered}
$$

since $\hat{s}_{B}>\hat{s}_{A}$. We can use the fact that $\frac{\partial s_{A}}{\partial p_{A}}=\frac{\partial s_{B}}{\partial p_{B}}\left(\frac{1+p_{B}}{s_{B}} \frac{s_{A}}{1+s_{A}}\right)^{2}$ in the right-hand side of the equation and simplify it to

$$
R H S=\frac{\partial s_{B}}{\partial p_{B}} \frac{1}{s_{B}^{2}\left(1+p_{A}\right)^{2}}\left[p_{B} s_{B}\left(1+p_{A}\right)^{2}-p_{A} s_{A}\left(1+p_{B}\right)^{2}\right]
$$




$$
>\frac{\partial s_{B}}{\partial p_{B}} \frac{1}{s_{B}^{2}\left(1+p_{A}\right)^{2}} \frac{s_{A}}{s_{B}^{2}\left(1+p_{A}\right)^{2}}\left(p_{B}-p_{A}\right)\left(1-p_{A} p_{B}\right)>0
$$

\subsection{Proof of Proposition 4.3}

The proof is based on the properties of $\sigma^{2}$ since they determine the shape of $\operatorname{Var}\left(\hat{K}_{g}\right)$, defined in condition $i$. of Lemma 4.2. We will use the following results.

Lemma 8.1 The variance of $\bar{\epsilon}$ is non-negative, $\sigma^{2}(\xi)>0 \forall \xi \in[0,0.5]$ and has only two zeroes: $\sigma^{2}=0$ at $\xi=0$ and $\xi=0.5$. At these points, its slope satisfies $\left.\frac{\partial \sigma^{2}(\xi)}{\partial \xi}\right|_{\xi=0}=0$ and $\left.\frac{\partial \sigma^{2}(\xi)}{\partial \xi}\right|_{\xi=0.5}<0$.

Proof The first property follows by definition: $\sigma^{2}=p_{A} p_{B}\left(\hat{s}_{A}-\hat{s}_{B}\right)^{2} \geq 0$. When $\xi=0$, $\hat{s}_{A}=\hat{s}_{B} \Rightarrow \sigma^{2}=0$. When $\xi=0.5, p_{A}=0 \Rightarrow \sigma^{2}=0$. Let $z=\hat{s}_{A}-\hat{s}_{B}$ and note that $p_{A} p_{B}=0.5^{2}-\xi^{2}$. Then

$$
\frac{\partial \sigma^{2}}{\partial \xi}=-2 \xi z^{2}+p_{A} p_{B} 2 z \frac{\partial z}{\partial \xi}
$$

where $\frac{\partial z}{\partial \xi}=2(1-\bar{\theta} \beta)\left[\left(1+p_{B}\right)^{-1}\left(2-\bar{\theta} p_{A}\right)^{-1}+\left(1+p_{A}\right)^{-1}\left(2-\bar{\theta} p_{B}\right)^{-1}\right]$. When $\xi=0$, $z=\left.0 \Rightarrow \frac{\partial \sigma^{2}}{\partial \xi}\right|_{\xi=0}=0$. Since $p_{A}=0$ when $\xi=0.5,\left.\frac{\partial \sigma^{2}}{\partial \xi}\right|_{\xi=0.5}<0$ follows.

Lemma 8.2 Let $\Xi \equiv\left\{\xi \in(0,0,5]: \frac{\partial \sigma^{2}(\xi)}{\partial \xi}=0\right\} \Rightarrow$ for any $\xi \in \Xi$, we have $\frac{\partial^{2} \sigma^{2}(\xi)}{\partial^{2} \xi}<0$.

Proof The second derivative of equation (31) is

$$
\frac{\partial^{2} \sigma^{2}}{\partial^{2} \psi}=-2 z^{2}-8 z \xi \frac{\partial z}{\partial \xi}+2 p_{A} p_{B}\left(\frac{\partial z}{\partial \xi}\right)^{2}+2 p_{A} p_{B} z \frac{\partial^{2} z}{\partial^{2} \xi}
$$

with

$$
\frac{\partial^{2} z}{\partial^{2} \xi}=4(1-\bar{\theta} \beta)\left[\frac{1+\bar{\theta} \beta p_{A}}{\left(1+p_{A}\right)^{2}\left(2-\bar{\theta} \beta p_{B}\right)^{2}}-\frac{1+\bar{\theta} \beta p_{B}}{\left(1+p_{B}\right)^{2}\left(2-\bar{\theta} \beta p_{A}\right)^{2}}\right] .
$$

Take $\xi^{*} \in \Xi$. We know that: (i) $z>0$, since $\xi>0$ and $s_{A}=s_{B} \Leftrightarrow \xi=0$ and (ii) $\xi^{*}$ solves $z=\frac{p_{A} p_{B}}{\xi} \frac{\partial z}{\partial \xi}$. Evaluating equation 31 at $\xi^{*}$ we obtain

$$
\left.\frac{\partial^{2} \sigma^{2}}{\partial^{2} \xi}\right|_{\xi \in \Xi}=2 \frac{z}{\xi}\left[\xi\left(0.5^{2}-\xi^{2}\right) \frac{\partial^{2} z}{\partial^{2} \xi}-\left(0.5^{2}+\xi^{2}\right) \frac{\partial z}{\partial \xi}\right] \text {. }
$$

Defining $\gamma_{i}=\left(1+p_{i}\right)\left(2-\bar{\theta} \beta p_{j}\right)$ for $j \neq i$, replacing the expression for $\frac{\partial^{2} z}{\partial^{2} \psi}$ into equation (33), and using condition (ii) we obtain

$$
\begin{aligned}
\left.\frac{\partial^{2} \sigma^{2}}{\partial^{2} \xi}\right|_{\xi \in \Xi}= & 4 \frac{z}{\xi}(1-\bar{\theta} \beta)\left(\gamma_{A}^{-2}\left[2 \xi\left(0.5^{2}-\xi^{2}\right)\left(1+\bar{\theta} \beta p_{A}\right)-\left(0.5^{2}+\xi^{2}\right) \gamma_{A}\right]-\right. \\
& \left.\gamma_{B}^{-2}\left[2 \xi\left(0.5^{2}-\xi^{2}\right)\left(1+\bar{\theta} \beta p_{B}\right)+\left(0.5^{2}+\xi^{2}\right) \gamma_{B}\right]\right)
\end{aligned}
$$


Since the second term is clearly positive (due to $\gamma_{i}>0 \forall i$ ),

$$
\begin{gathered}
\left.\frac{\partial^{2} \sigma^{2}}{\partial^{2} \xi}\right|_{\xi \in \Xi}<4 \frac{z}{\xi}(1-\bar{\theta} \beta) \gamma_{A}^{-2}\left[2 \xi\left(0.5^{2}-\xi^{2}\right)\left(1+\bar{\theta} \beta p_{A}\right)-\left(0.5^{2}+\xi^{2}\right) \gamma_{A}\right] \\
<4 \frac{z}{\xi}(1-\bar{\theta} \beta) \gamma_{A}^{-2}\left(1+p_{A}\right)\left[2 \xi\left(0.5^{2}-\xi^{2}\right)-\left(0.5^{2}+\xi^{2}\right)\left(2-\bar{\theta} \beta p_{A}\right)\right]
\end{gathered}
$$

using the fact that $\bar{\theta} \beta<1$. Simplifying, we obtain

$$
<4 \frac{z}{\xi}(1-\bar{\theta} \beta) \gamma_{A}^{-2}\left(1+p_{A}\right)\left[0.5^{2}(-1.5+\xi)+\xi^{2}(-2+\bar{\theta} \beta / 2)-\xi^{3}(2+\bar{\theta} \beta)<0 .\right.
$$

Claim 8.1 There exists a unique $\xi^{*} \in \Xi$.

Proof Existence by continuity of $\sigma^{2}(\xi)$ and Lemmas 8.1 and 8.2. The function $\sigma^{2}(\xi)$ is continuously differentiable and strictly positive in the interval $(0,0.5)$ and equal to zero at $\xi=0$ and $\xi=0.5$. Hence a point in $\Xi$ must exist.

Uniqueness by contradiction. Suppose $\exists$ at least one value $\tilde{\xi} \in \Xi$ such that $\frac{\partial^{2} \sigma^{2}}{\partial^{2} \xi} \geq 0$, because the function $\sigma^{2}(\xi)$ is continuous in $\xi$ and $\sigma^{2}=0$ at the extremes, $\xi=0.5$ and $\xi=0$, as shown in Lemma 8.1. But this contradicts Lemma 8.2, which proved that $\sigma^{2}(\xi)$ is strictly concave around any point where the first derivative is zero.

\subsection{Proof of Proposition 6.1}

Guess a constant probability $p_{i}\left(K_{g}\right)=p_{i}$ and a constant investment share $h_{i}\left(K_{g}\right)=s_{i} \tilde{A} K_{g}^{\bar{\theta}}$. From Proposition 4.1 we verify the guess for $h_{i}\left(K_{g}\right)$ given a constant $p_{i}$, where $s_{B}$ is defined in equation 30.

To verify that $p_{i}$ is constant, note that the value functions satisfy

$$
\begin{aligned}
V_{j}\left(K_{g}\right) & =\bar{\nu}_{j}+\nu_{j} \ln \left(K_{g}\right) . \\
W_{j}\left(K_{g}\right) & =\bar{\omega}_{j}+\omega_{j} \ln \left(K_{g}\right),
\end{aligned}
$$

where

$$
\begin{gathered}
\nu_{j}=\frac{\bar{\theta}\left(2-\bar{\theta} \beta p_{i}\right)}{1-\bar{\theta} \beta} \text { and } \omega_{j}=\frac{\bar{\theta}\left(1+\bar{\theta} \beta p_{j}\right)}{1-\bar{\theta} \beta}, \\
\bar{\nu}_{j}=\frac{1}{1-\beta}\left\{\beta ( 1 - p _ { j } ) \left[\ln \left(\frac{1}{2}\left(1-s_{i}\right) \tilde{A}\right)+\beta\left[p_{j} \nu_{j}+\left(1-p_{j}\right) \omega_{j}\right] \ln \left(s_{i} \tilde{A}\right)\right.\right. \\
\left.+\left[1-\beta\left(1-p_{j}\right)\right]\left[2 \ln \left(\frac{1}{2}\left(1-s_{j}\right) \tilde{A}\right)+\beta\left[p_{j} \nu_{j}+\left(1-p_{j}\right) \omega_{j}\right] \ln \left(s_{j} \tilde{A}\right)\right]\right\}, \\
\bar{\omega}_{j}=\frac{1}{1-\beta\left(1-p_{j}\right)}\left\{\ln \left(\frac{1}{2}\left(1-s_{i}\right) \tilde{A}\right)+\beta\left[p_{j} \bar{\nu}_{j}+\left[p_{j} \nu_{j}+\left(1-p_{j}\right) \omega_{j}\right] \ln \left(s_{i} \tilde{A}\right)\right]\right\} .
\end{gathered}
$$

Replace eq. (34) and eq. (35) into eq. (17) to obtain the expression that determines $\psi^{*}\left(K_{g}\right)$.

Finally, we verify that probabilities are constant and that governments choose to invest a proportion of output. Notice that these rules are increasing in capital, differentiable and invertible. 


\subsection{Proof of Proposition 6.2}

The proof will be done in two steps.

Step 1: Let $\eta=0$. Then, there exists a symmetric solution.

Substitute eq. (21) into eq. (22), and evaluate at $p_{A}\left(K_{g}\right)=\frac{1}{2}-\eta+\psi^{*}\left(K_{g}^{\prime}\right)$ to obtain

$$
p_{A}=\frac{1}{2}-\eta+\frac{3}{2}\left\{\ln \left(\frac{2-\bar{\theta} \beta p_{A}}{2-\bar{\theta} \beta\left(1-p_{A}\right)}\right)+\frac{\bar{\theta} \beta}{1-\beta \bar{\theta}} \ln \left(\frac{1+p_{A}}{2-\bar{\theta} \beta\left(1-p_{A}\right)} \frac{2-\bar{\theta} \beta p_{A}}{2-p_{A}}\right)\right\} .
$$

At $\eta=0, p_{A}=\frac{1}{2}$ solves equation (36). Replace this into eq. (21) to obtain $s_{A}=s_{B}$.

Step 2: Let $\eta>0$. Then, there exists an asymmetric solution

The LHS of equation (36) is increasing in $p_{A}$. The RHS is also increasing in $p_{A}$ for any $p_{A} \in[0,1]$ since

$$
\frac{\partial \operatorname{RH} S\left(p_{A}\right)}{\partial p_{A}}=\frac{3}{2} \bar{\theta} \beta\left(\frac{p_{A}}{\left(2-\bar{\theta} \beta p_{A}\right)\left(2-p_{A}\right)}+\frac{1-p_{A}}{\left(2-\bar{\theta} \beta\left(1-p_{A}\right)\right)\left(1+p_{A}\right)}\right)>0 .
$$

From Step 1, there exists a solution at $\eta=0$. Now let $\eta>0$. The LHS remains unchanged and the RHS shifts to the left. Hence $p_{A}<\frac{1}{2}$ and $p_{B}>\frac{1}{2}$. Replace these in eq. (21) for $i=\{A, B\}$ to see that $s_{A}<s_{B}$.

\subsection{Numerical Appendix}

\subsubsection{Parameters used in numerical examples}

A time period represents a year, so the discount factor is $\beta=0.95$. Following Greenwood, Hercowitz and Huffman (1988) I assume that the elasticity of labor supply $\epsilon$ equals 2 . The level of productivity $A$ is normalized to one. There are three non-standard parameters in this model: The elasticity of public capital $\theta$, the fixed cost of providing public goods $G$, and the popularity advantage $\xi$. I choose the three parameters so that simulated moments at the political equilibrium match three target moments in the data. The first target is mean non-defense public investment as a proportion of GDP in the US for the period 1929-2006 $(G N D I / Y)$. The second target is average non-defense public consumption as a proportion of output, for the same time period $(G N D C / Y)$. All figures are obtained from the NIPA tables. The third target is computed so that the equilibrium advantage of party $B$, given by $p_{B}-p_{A}$ in the model, matches the average advantage obtained by the Democrats during all congressional elections to the House of Representatives between 1929 and $2006(A D)$. The variable is computed as follows. Let $s h_{t}(i)=\frac{i_{t}}{D_{t}+R_{t}}$ denote the share of seats obtained by party $i \in\{R, D\}$ in the House of Representatives in Congress $t \in\left\{70^{n t}, \ldots, 109^{t h}\right\}$ (that is, covering the period 1929-2006). Following Diermeier, Keane and Merlo (2005) the advantage of party $D$ at each period of time is simply $A d v_{t}=s h_{t}(D)-s h_{t}(R)$.

I simulated the political equilibrium for 5000 periods and discarded the first 1000 to eliminate the effects of initial conditions. Table I summarizes the value of the parameters obtained from the calibration, together with the target variables. 


\begin{tabular}{|c|c|c|c|}
\hline Variable & Parameter & Target & Target Value \\
\hline Elasticity of public investment & $\theta=0.039$ & Public Investment/Output & $G N D I / Y=2.88$ \\
Fixed cost of public goods & $G=0.063$ & Public Spending/Output & $G N D C / Y=13.84$ \\
Popularity advantage & $\xi=0.068$ & Democrat advantage & $A D=0.145$ \\
\hline
\end{tabular}

The value of $\theta$ is in line with empirical estimates and close to the estimate used in Baxter and King (1993), who set the elasticity of public capital to 0.05. While they use the same target - public investment as a ratio of output - to calibrate the model, their measure of investment includes defense expenditures, while mine excludes them. If I were to include defense expenditures as well, I would obtain a value closer to Baxter and King's. The parameter $G$ captures expenditures that have not been modeled (such as defense spending). To the extent of my knowledge, this is the first time an attempt to estimate the parameter $\xi$ has been done in a calibrated political economy model. Therefore, there is no counterpart in the literature. As we will see in the next section, assuming a constant value for $\xi$ is clearly a simplification, since its value has fluctuated over the time interval. However, using a stochastic popularity advantage would complicate the solution presented in this paper, and it is left for an extension. ${ }^{13}$

\footnotetext{
${ }^{13}$ See Battaglini (2010) for en environment in which a party's advantage changes over time in a symmetric environment with commitment.
} 
8.10.2 Data Sample

\begin{tabular}{llll}
\hline $\begin{array}{l}\text { Developed Economies } \\
\text { Country }\end{array}$ & Period & Emerging Economies & \\
\hline \hline Australia & $1970-2003$ & Algeria & Period \\
Austria & $1976-2003$ & Bangladesh & $1969-2003$ \\
Canada & $1960-2003$ & Brazil & $1969-2003$ \\
Finland & $1976-2003$ & Chile & $1980-2003$ \\
France & $1970-2003$ & China & $1981-2003$ \\
Germany & $1979-2003$ & Dominican Republic & $1981-2003$ \\
Ireland & $1976-2003$ & Egypt & $1980-2003$ \\
Italy & $1977-2003$ & Indonesia & $1969-1989$ \\
Japan & $1960-2003$ & Iran & $1975-2003$ \\
Jordan & $1963-2003$ & Korea & $1969-2003$ \\
Netherlands & $1980-2003$ & Mexico & $1963-2003$ \\
New Zealand & $1980-2003$ & Morocco & $1969-2003$ \\
Norway & $1976-2003$ & Pakistan & $1969-2003$ \\
Portugal & $1980-2003$ & Peru & $1963-2003$ \\
Spain & $1980-2003$ & Philippines & $1969-2003$ \\
Switzerland & $1983-2003$ & South Africa & $1969-2003$ \\
United Kingdom & $1960-2003$ & Uganda & $1980-2003$ \\
United States & $1960-2003$ & Zimbabwe & $1983-2003$ \\
\hline
\end{tabular}




\section{References}

[1] Alesina, Alberto and Nouriel Roubini (1997). Political cycles and the macroeconomy. MIT. USA.

[2] Alesina, Alberto and Guido Tabellini (1990). "A positive theory of fiscal deficits and government debt," Review of Economic Studies, 57, 3: 403-14.

[3] Amador, Manuel (2008). "Sovereign debt and the tragedy of the commons". Mimeo.

[4] Azzimonti, Marina (2010) "Barriers to investment in polarized societies," American Economic Review, forthcoming.

[5] Azzimonti, Marina and Matthew Talbert (2011) "Partisan cycles and the consumption volatility puzzle," Mimeo.

[6] Bachman Rudiger and Jinhui Bai (2010) "Government purchases over the business cycle: The role of economic and political inequality," NBER Working Papers 16247.

[7] Battaglini, Marco (2010). "Dynamic electoral competition and constitutional design," Mimeo.

[8] Battaglini, Marco and Stephen Coate (2007). "Inefficiency in legislative policymaking: A dynamic analysis," American Economic Review,97, 1: 118-149.

[9] Baxter, Marianne and Robert King (1993). "Fiscal Policy in General Equilibrium," American Economic Review, 83, 3: 315-34.

[10] Besley, Timothy and Stephen Coate (1998). "Sources of inefficiency in a representative democracy: a dynamic analysis," American Economic Review, 88, 1: 139-56.

[11] Besley, Timothy, Ilzetzki, Ethan, and Torsten Persson (2010). "Weak states and steady states: The dynamics of fiscal capacity". Mimeo.

[12] Brown, Robert and John Bruce (2008). "Political parties in state and nation: Party advantage and party competition in a federal setting". Party Politics, 8, 6:635656.

[13] Caballero, Ricardo and Pierre Yared (2010). "Future rent-seeking and current public savings," Journal of International Economics 82: 124136.

[14] Cuadra, Gabriel and Horacio Sapriza (2008). "Sovereign default, interest rates and political uncertainty in emerging markets," Journal of International Economics, $76,1: 78-88$.

[15] Debortoli, Davide and Ricardo Nunes (2008). "Political disagreement, lack of commitment and the level of debt," International Finance Discussion Papers 938, Board of Governors of the Federal Reserve System (U.S.). 
[16] Debortoli, Davide and Ricardo Nunes (2010). "Fiscal policy under loose commitment," Journal of Economic Theory, 145, 3:1005-1032.

[17] Devereux, Michael and Jean-Francois Wen (1998). "Political instability, capital taxation and growth," European Economic Review, 42: 1635-1651.

[18] Diermeier, Daniel, Keane, Michael, and Antonio Merlo (2005) "A political economy model of Congressional careers," American Economic Review, 95, 1:347-373.

[19] Drazen, Allen (2000). Political economy in macroeconomics. Princeton Univesity Press, Princeton, New Jersey.

[20] Farhi, Emmanuel and Ivan Werning (2008). "The political economy of nonlinear capital taxation," Mimeo.

[21] Greenwood, Jeremy, Hercowitz, Zvi, and Huffman, G. (1988). "Investment, capacity utilization, and the real business cycle," American Economic Review, 78, $3: 402-17 /$

[22] Hamilton, James (1994), Time Series Analysis, Princeton University Press, Princeton, New Jersey.

[23] Hassler, John, Mora Jose, Storesletten Kuetil, and Fabrizio Zilibotti (2004). "The survival of the welfare state," American Economic Review, 93, 1: 87 112.

[24] Hassler, John, Storesletten, Kjetil and Fabrizio Zilibotti (2007). "Democratic public good provision," Journal of Economic Theory, 133, 1: 127-151.

[25] Ilzetzki, Ethan (2011) "Rent-seeking distortions and fiscal procyclicality," Journal of Development Economics, 96, 1: 30-46.

[26] Kaminsky, Graciela, Carmen Reinhart, and Carlos Végh (2004) "When it rains, it pours: Procyclical capital flows and macroeconomic policies'. NBER macroeconomics annual 2004, ed. Mark Gertler and Ken Rogoff, 11-82. Cambridge,

[27] Klein, Paul, Krusell, Per, and Victor Rios-Rull (2008). "Time-consistent public expenditures," Review of Economic Studies, 75, 3: 789-808.

[28] Krusell, Per and Victor Rios-Rull (1999). "On the size of government: Political economy in the neoclassical growth model," American Economic Review, 89, 5: 11561181.

[29] Kumhof, Michael and Irina Yakadina (2007). "Politically optimal fiscal policy," IMF Working Paper WP 07-68.

[30] Lagunoff, Roger and Jinhui Bai (2010). "On the faustian dynamics of policy and political power," Review of Economic Studies, forthcoming. 
[31] Lindbeck, A. And Weibull, J. (1993). "A model of political equilibirum in a representative democracy," Journal of Public Economics 51:195-209.

[32] Milesi-Ferretti, Gian and Enrico Spolaore (1994). "How cynical can an incumbent be? Strategic policy in a model of government spending," Journal of Public Economics, 55: 121-140.

[33] Persson, Torsten and Lars Svensson (1989). "Why a stubborn conservative would run a deficit: Policy with time-inconsistent preferences," The Quarterly Journal of Economics, May: 325-345.

[34] Persson, Torsten and Guido Tabellini (2000). Political economics: explaining economic policy. The MIT Press, Cambridge Massachusetts. London, England.

[35] Sleet, Chris and Sevin Yeltekin (2008). "Politically credible social insurance," Journal of Monetary Economics, 55, 1: 129-151.

[36] Song, Zheng (2010) "Persistent ideology and the determination of public policy over time," International Economic Review, forthcoming.

[37] Stokes, David (1992). "Valence politics," in Electoral Politics by D. Kavabagh. Oxford: Clarendon Press: 141-64. 